\title{
All Layers of Medial Entorhinal Cortex Receive Presubicular and Parasubicular Inputs
}

\author{
Cathrin B. Canto, ${ }^{1,2}$ Noriko Koganezawa, ${ }^{1}$ Prateep Beed, ${ }^{3}$ Edvard I. Moser, ${ }^{1}$ and Menno P. Witter ${ }^{1,2}$ \\ ${ }^{1}$ Kavli Institute for Systems Neuroscience, Centre for the Biology of Memory, Norwegian University of Science and Technology, NTNU, NO-7491 \\ Trondheim, Norway, ${ }^{2}$ VU University Medical Center, Department of Anatomy and Neurosciences, NL-1081 BT Amsterdam, The Netherlands, and \\ ${ }^{3}$ Neuroscience Research Center, Charité-Universitätsmedizin Berlin, 10117 Berlin, Germany
}

The medial entorhinal cortex (MEC), presubiculum (PrS), and parasubiculum (PaS) are interconnected components of the hippocampalparahippocampal spatial-representation system. Principal cells in all layers of MEC show signs of directional tuning, overt in head direction cells present in all layers except for layer II, and covert in grid cells, which are the major spatially modulated cell type in layer II. Directional information likely originates in the head direction-vestibular system and $\mathrm{PrS}$ and $\mathrm{PaS}$ are thought to provide this information to MEC. Efferents from PaS and PrS show a selective laminar terminal distribution in MEC superficial layers II and III, respectively. We hypothesized that this anatomically determined laminar distribution does not preclude monosynaptic interaction with neurons located in deeper layers of MEC in view of the extensive apical dendrites from deeper cells reaching layers II and III. This hypothesis was tested in the rat using tilted in vitro slices in which origins and terminations of $\mathrm{PrS}$ and $\mathrm{PaS}$ fibers were maintained, as assessed using anterograde anatomical tracing. Based on voltage-sensitive dye imaging, multipatch single-cell recordings, and scanning photostimulation of caged glutamate, we report first that principal neurons in all layers of MEC receive convergent monosynaptic inputs from PrS and PaS and second, that elicited responses show layer-specific decay times and frequency-dependent facilitation. These results indicate that regardless of their selective laminar terminal distribution, $\mathrm{PrS}$ and $\mathrm{PaS}$ inputs may monosynaptically convey directional information to principal neurons in all layers of MEC through synapses on their extensive dendritic arbors.

\section{Introduction}

Individual neurons in all layers of the medial entorhinal cortex (MEC) represent different aspects of space, including position (grid cells), direction (head direction cells), borders (border or boundary vector cells) or combinations of these features (Hafting et al., 2005; Sargolini et al., 2006; Solstad et al., 2008; Burgess and O'Keefe, 2011). Directional information has been postulated as relevant for the emergence of stable grid cell properties (Fuhs and Touretzky, 2006; McNaughton et al., 2006; Burgess et al., 2007) and temporarily silencing hippocampal influence on MEC unmasks clear directional features in grid cells (Bonnevie et al., 2011). Temporal inactivation of the medial septum disrupts grid cell firing but does not affect head directional properties of neurons (Brandon et al., 2011; Koenig et al., 2011). Directional in-

Received July 24, 2012; revised Sept. 25, 2012; accepted 0ct. 11, 2012.

Author contributions: C.B.C. and M.P.W. designed research;C.B.C., N.K., and P.B. performed research;C.B.C. and

M.P.W. analyzed data; C.B.C., E.I.M., and M.P.W. wrote the paper.

The authors declare no competing financial interests.

This work was supported by the Kavli Foundation, and the Norwegian Research Council (Centre of Excellence Grant No. 145993, Equipment Grant No. 181676, and Research Grant No. 191929) and the European Commission ("Spacebrain," No. 200873). We thank Helen Scharfman, Jonathan Jay Couey, Mayank Mehta, and Dietmar Schmitz for comments and advice during the preparation of this manuscript and Harry Uylings for statistical advice, Rafal Czajkowski and Ellen Husby for help with the confocal analyses, Jean Luc Boulland for help setting up juvenile rat surgeries, and Natalia Kononenko and Ragnhild Gisetstad for technical assistance.

Correspondence should be addressed to Menno P. Witter, Kavli Institute for Systems Neuroscience, Centre for the Biology of Memory, Medical-Technical Research Center, Postboks 8905, N0-7491 Trondheim, Norway. E-mail: menno.witter@ntnu.no.

DOI:10.1523/JNEUROSCI.3526-12.2012

Copyright $\odot 2012$ the authors $\quad 0270-6474 / 12 / 3217620-12 \$ 15.00 / 0$ formation is thus widespread in MEC, but is likely not generated within the network, since necessary inputs to MEC from the vestibular system, mediated by way of the lateral mammillary-anterior thalamic route (Taube, 1995; Stackman and Taube, 1998; Vann, 2010), are either sparse and restricted to the extreme dorsocaudal part (Shibata, 1993; Van Groen and Wyss, 1995) or absent (Kerr et al., 2007). Vestibular inputs, however, specifically influence the presubiculum (PrS) and parasubiculum (PaS; Taube, 2007) known to give rise to $\sim 35 \%$ of the hippocampalparahippocampal and $\sim 15 \%$ of the total cortical inputs to MEC (Kerr et al., 2007).

Projections from PrS and PaS show a strikingly laminar terminal distribution in MEC, the former distributing to MEC layers I and III, and the latter terminating in layer II (Köhler, 1985; Caballero-Bleda and Witter, 1993). Both inputs form synaptic contacts with principal neurons and interneurons that reside in the targeted layers (Caballero-Bleda and Witter, 1994; van Haeften et al., 1997; Tolner et al., 2007). Still, directionally tuned neurons are not only present in layer III but also in layers $\mathrm{V}$ and VI (Sargolini et al., 2006), while layer II grid cells may reveal directional tuning under certain experimental conditions (Bonnevie et al., 2011). In addition, grid cells in different layers of MEC often show remarkably consistent orientations (Sargolini et al., 2006). This suggests that neurons in all layers of MEC (1) receive inputs from $\mathrm{PrS}$ and $\mathrm{PaS}$ directly or (2) receive these inputs via an intrinsic network connecting neurons in layers II and III to those in deeper layers. Although these superficial-to-deep connections likely exist (Iijima et al., 1996), they are not considered 


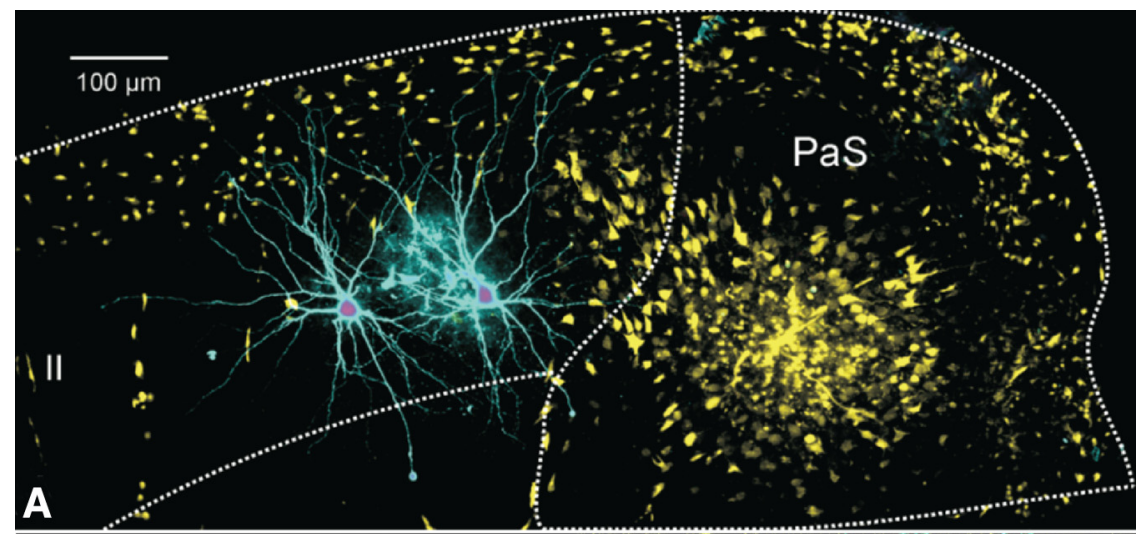

PrS or PaS and hippocampus, respectively. Injection coordinates were adjusted from the Sherwood atlas of the developing rat brain (Sherwood and Timiras, 1970). DiI was injected by applying alternating $7 \mathrm{~s}$ on/off current pulses of $5 \mu \mathrm{A}$ for $10 \mathrm{~min}$, and for Alexa $488 \mathrm{DA}$ $7 \mu \mathrm{A}$ current pulse alternations were used for $15 \mathrm{~min}$. Pups survived for 3-10 d.

\section{Slice preparation}

For voltage-sensitive dye (VSD) imaging and extracellular stimulation experiments, 72 P14P31Sprague Dawley rats of either sex were anesthetized with isoflurane (Intervet International), subsequently decapitated, and the brain quickly removed from the skull and

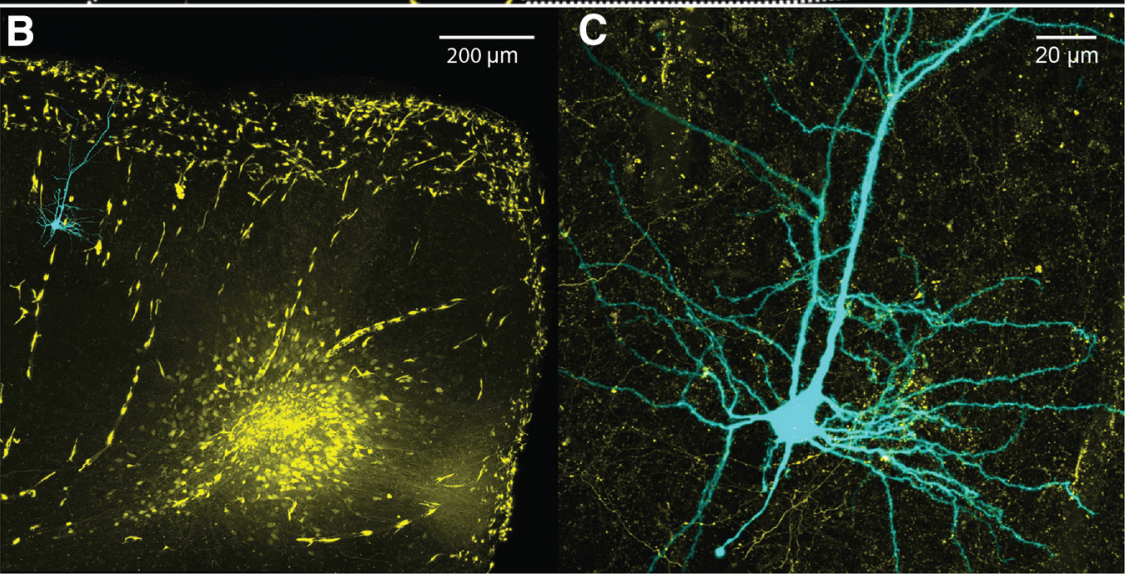
placed in oxygenated $\left(95 \% \mathrm{O}_{2}-5 \% \mathrm{CO}_{2}\right)$ icecold artificial CSF (ACSF) containing the following (in $\mathrm{mm}$ ): $126 \mathrm{NaCl}, 3 \mathrm{KCl}, 1.25$ $\mathrm{NaH}_{2} \mathrm{PO}_{4}, 3 \mathrm{MgSO}_{4}, 1 \mathrm{CaCl}_{2}, 10$ glucose, and $26 \mathrm{NaHCO}_{3}$. For glutamate uncaging, semihorizontal brain slices were obtained from P16-P26 old Wistar rats. The procedure was similar to that described above, except that after removal of the hemispheres, they were placed in oxygenated ice-cold ACSF containing the following (in $\mathrm{mM}$ ): $87 \mathrm{NaCl}, 2.5 \mathrm{KCl}$, $1.25 \mathrm{NaH}_{2} \mathrm{PO}_{4}, 7 \mathrm{MgCl}_{\mathrm{s}}, 0.5 \mathrm{CaCl}_{2}, 75$ saccharose, 25 glucose, and $26 \mathrm{NaHCO}_{3}$. To maintain the connectivity between the PrS, PaS, and MEC, 400- $\mu \mathrm{m}$-thick semihorizontal slices were cut with an angle of $10-15^{\circ}$, while the brain was still superfused with saturated icecold ACSF (Vibratome 1000; Vibratome). According to anatomical tracing data (Honda and Ishizuka, 2004), slices cut at this angle will likely conserve a substantial part of the projections from $\mathrm{PrS}$ and $\mathrm{PaS}$ to MEC by assuring that a more mediodorsal level of PrS and $\mathrm{PaS}$ is in the same slice as the connected more lateroventral level of MEC. This assumption was

to be elaborate (Witter and Amaral, 2004; Canto et al., 2008). Therefore, we tested whether neurons in all layers receive monosynaptic inputs from $\mathrm{PrS}$ and $\mathrm{PaS}$ in an in vitro slice preparation using voltage-sensitive dye imaging, single-cell patch recordings, and scanning photo stimulation with caged glutamate.

The results indicate that principal neurons in all MEC layers receive monosynaptic inputs from PrS and PaS. These shared inputs thus provide a parsimonious substrate for the prominent directional tuning of head direction cells and the coherent orientational tuning of grid cells in all layers of MEC.

\section{Materials and Methods}

Animal experiments were performed in accordance with the rules and directives set by local governments and universities and the European Community on animal well being.

\section{Anatomical tracer application}

Albino Sprague Dawley rats of either sex [postnatal (P)10-P24; $N=24$ ] were injected with a $10 \%$ diluted anterograde tracer Alexa Fluor 488 dextran amine (Alexa $488 \mathrm{DA}$; Invitrogen) dissolved in $25 \mathrm{~mm}$ phosphate buffer (PB; pH 7.5) and a retrograde tracer, 1,1-dioctadecyl-3,3,3,3tetramethylindocarbocyanine perchlorate (DiI; Invitrogen) dissolved in $100 \%$ ethanol at $5 \mathrm{mg} / \mathrm{ml}$. Tracer injection was performed under isoflurane anesthesia (Intervet International). After induction, the rats were subcutaneously injected with the analgesic Rimadyl (carprofen, 6-chloro- $\alpha$-methyl- $9 H$-carbazole-2-acetic acid; $50 \mathrm{mg} / \mathrm{ml}$; Pfizer,). Glass micropipettes with a tip diameter of $15 \mu \mathrm{m}$ filled with Alexa 488 DA or 20 $\mu \mathrm{m}$ tip diameter filled with $\mathrm{DiI}$, were stereotactically positioned into the validated in the first series of recording experiments.

VSD imaging was performed at $32^{\circ} \mathrm{C}$. Each slice was transferred onto a fine-mesh membrane filter (Omni pore membrane filter, JHWP01300; Millipore) held in place by a thin Plexiglas ring (11 $\mathrm{mm}$ inner diameter; $15 \mathrm{~mm}$ outer diameter; $1-2 \mathrm{~mm}$ thickness), maintained in a moist interface chamber, containing the previously used ACSF with $2 \mathrm{~mm} \mathrm{MgSO}_{4}$ and $2 \mathrm{mM} \mathrm{CaCl}_{2}$, continuously supplied with a moistened mixture of the $\mathrm{O}_{2}$ and $\mathrm{CO}_{2}$ gas (Koganezawa et al., 2008). Extracellular stimulation and glutamate uncaging experiments were performed at $35^{\circ} \mathrm{C}$. Slices were transferred to a slice chamber with oxygenated ACSF containing the following (in mM): $119 \mathrm{NaCl}, 26 \mathrm{NaHCO}_{3}, 10$ glucose, $2.5 \mathrm{KCl}, 1$ $\mathrm{NaH}_{2} \mathrm{PO}_{4}, 1.3 \mathrm{MgCl}_{2}$, and $2.5 \mathrm{CaCl}_{2}$ in case of uncaging but $126 \mathrm{NaCl}, 3$ $\mathrm{KCl}, 1.25 \mathrm{NaH}_{2} \mathrm{PO}_{4}, 2 \mathrm{MgSO}_{4}, 2 \mathrm{CaCl}_{2}, 10$ glucose, and $26 \mathrm{NaHCO}_{3}$ in case of extracellular stimulation. For all experiments slices rested for at least $1 \mathrm{~h}$ until used one by one in the recording chamber superfused with ACSF.

\section{Electrophysiology}

VSD imaging. The slice was positioned under a fluorescence microscope (Axio Examiner; Zeiss) and stained for 3 min with VSD RH-795 (0.5 $\mathrm{mg} / \mathrm{ml}$ ACSF; Koganezawa et al., 2008). Excitation light (filtered at $535 \pm$ $25 \mathrm{~nm}$ bandpass) was reflected down onto the preparations by a dichroic mirror (half-reflectance wave length of $580 \mathrm{~nm}$ ). Epifluorescence through a long-wavelength pass filter ( $50 \%$ transmittance at $590 \mathrm{~nm})$ was detected with a CMOS-camera (MiCAMUltima; BrainVision, $100 \times 100$ pixels array). When the optical recording was triggered, an electronically controlled shutter built into the light source (HL-151; Brain Vision) was opened for $500 \mathrm{~ms}$ before the start of recording to avoid both mechanical disturbance caused by the shutter system and rapid bleaching of the dye. 


\section{A VSD imaging}
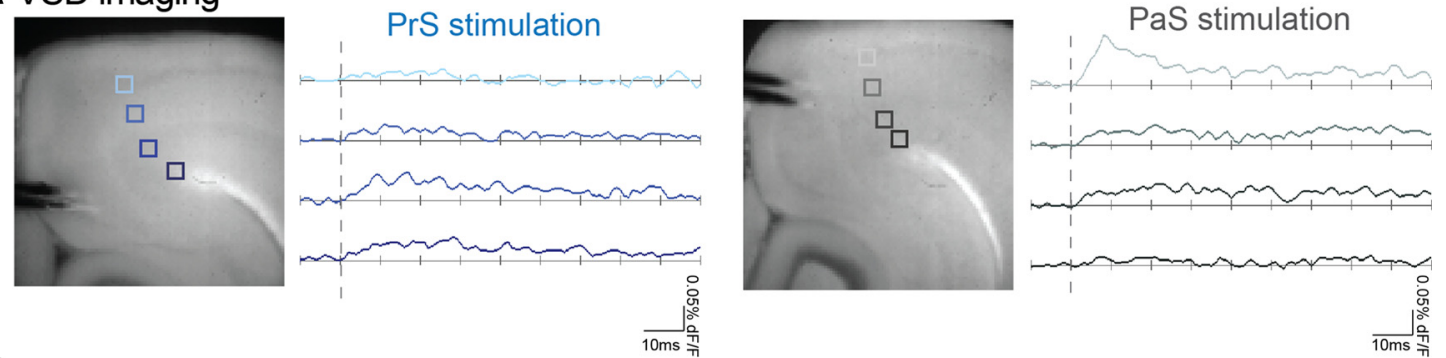

B VSD imaging

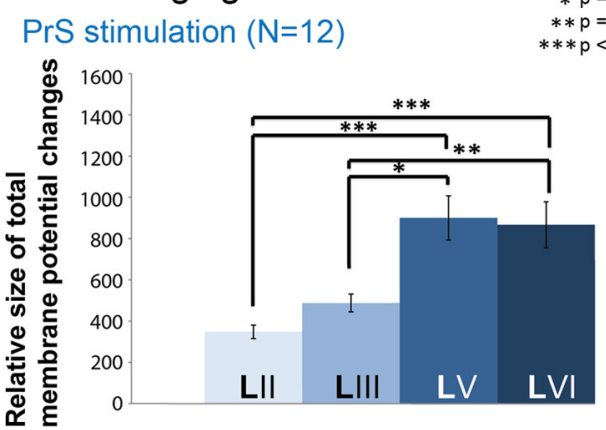

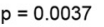

$* p=0.0046$

$p<0.0010$

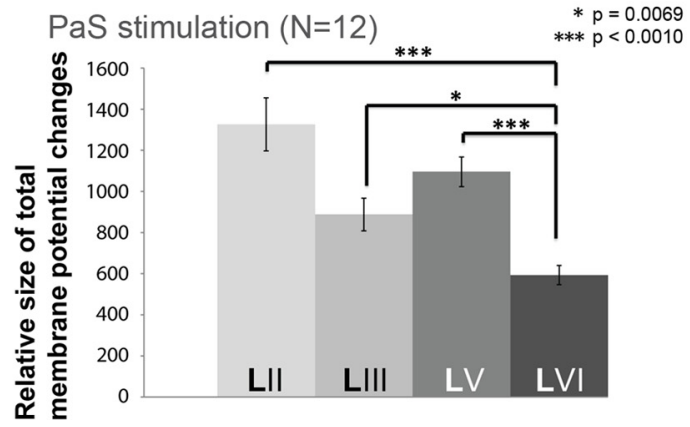

Figure 2. Bipolar stimulation in PrS (blue) or PaS (gray) evoked responses in all layers of MEC as measured with VSD imaging. $\boldsymbol{A}$, Images of a representative horizontal slice illustrating the position of the bipolar stimulation electrode in PrS (left) and PaS (right) and the position of four voxels in layers II-VI for which the optical responses are presented. Traces to the right of the images are color coded related to the voxels in the case of PrS stimulation (blue tones) and PaS stimulation (gray tones). Dashed vertical lines indicate the onset of stimulation. $\boldsymbol{B}$, Histograms presenting the relative size of total membrane potential changes for layers II-VI after stimulating PrS (left) or PaS (right; bars represent the mean of 12 slices $\pm S E M$ ). PrS stimulation: $N=12 ; d f 3, \chi^{2} 24.79, p=0.0010$; PaS stimulation: $N=12 ; d f 3, \chi^{2} 23.70, p<0.001$.

After starting, the optical baseline was allowed to stabilize for $50 \mathrm{~ms}$ before stimuli were delivered. For all experiments, 512 frames at a rate of $1.0 \mathrm{~ms} /$ frame were acquired. To represent the spread of neural activity, we superimposed color-coded optical signals on the bright-field image. In this procedure, we applied a color code to the fraction of the optical signal, which exceeded the baseline noise. To reduce baseline noise, we averaged eight identical recordings acquired with a 3 s interval directly in the frame memory. Extracellular stimulation was applied to PrS or PaS with a tungsten bipolar electrode with a tip separation of $150 \mu \mathrm{m}$. Single pulses of $0.6 \mathrm{~mA}$ for $300 \mu \mathrm{s}$ duration were used. The place of stimulation was chosen as indicated for single-neuron recordings (see below).

Single-neuron recordings. Up to three simultaneous whole-cell currentclamp recordings of MEC neurons were done under visual guidance using infrared differential interference contrast video microscopy. Recorded neurons were classified as principal neurons based on previously established physiological and morphological properties (Canto and Witter, 2012).

Patch pipettes were pulled from standard-walled borosilicate capillaries (GC120F-10; Harvard Apparatus) with a resistance between 4 and 7 $\mathrm{M} \Omega$ containing the following (in $\mathrm{mM}$ ): $110 \mathrm{~K}$-gluconate, 10 HEPES, 4 ATP-Mg, $0.3 \mathrm{GTP}, 10$ Naphosphocreat, and $10 \mathrm{KCl}$ with $5 \mathrm{mg} / \mathrm{ml}$ biocytin, $\mathrm{pH} 7.3$, adjusted with $1 \mathrm{~m} \mathrm{KOH}$, and an osmolarity of $\sim 290 \mathrm{M}$. The seal resistance was $>1 \mathrm{G} \Omega$. Recordings were made with a Multiclamp 700A Amplifier (Molecular Devices) in bridge mode. Capacitance compensation was maximal and bridge balance adjusted. The signal was lowpass filtered at $3 \mathrm{kHz}$ and acquired at a sampling rate of $5 \mathrm{kHz}$ with an Instrutech ITC-18 board (Instrutech). During recordings neurons were filled with biocytin. Recordings were either made in the area in MEC that showed anterogradely fluorescent axonal labeling originating from PrS or PaS or in comparable locations in case of noninjected animals (see Fig. 1). For all cells we also measured intrinsic membrane properties as previously described (Canto and Witter, 2012).

The PrS or PaS was stimulated with a stimulation electrode that was covered with a glass pipette (tip diameter of $\sim 1-2 \mu \mathrm{m}$ ) filled with ACSF or with a tungsten bipolar electrode with a tip separation of $150 \mu \mathrm{m}$. The place of stimulation was either chosen to coincide with the area that showed a high level of fluorescent tracer in the injection site of the an- terograde tracer (Fig. 1A,B), or in case of noninjected animals, the stimulation site was in comparable locations, chosen by visual guidance with a low and high-magnification lens $(2.5$ or $10 \times$ water $)$. Inputs from superficial PrS or PaS layers were stimulated locally with different lengths, strengths, and frequencies controlled by Igor, Master 8 , and the stimulation isolator box itself. Each change in parameters was tested in response to 50 stimulus trains of $1 \mathrm{~s}$ duration. The parameters tested were as follows: $0 \mathrm{mV} / 10 \mu \mathrm{s}, 0.9 \mathrm{mV} / 10 \mu \mathrm{s}, 9 \mathrm{mV} / 10 \mu \mathrm{s}, 22.5 \mathrm{mV} / 10 \mu \mathrm{s}, 45$ $\mathrm{mV} / 10 \mu \mathrm{s}, 67.5 \mathrm{mV} / 10 \mu \mathrm{s}$, and $90 \mathrm{mV} / 10 \mu \mathrm{s}$ and as a control $0 \mathrm{mV} / 1 \mathrm{~ms}$, $0 \mathrm{mV} / 0 \mathrm{~s}$, and $90 \mathrm{mV} / 0 \mathrm{~s}$ positive pulses. Repetitive stimulation was performed with $90 \mathrm{mV} / 10 \mu$ s pulses after confirmation that there was no change in the evoked postsynaptic potential (ePSP) properties comparing strong and weak stimulations and no short-term-dependent plasticity, meaning equilibrium in ePSP size was reached. Bipolar stimulation was performed using $300 \mu \mathrm{s}$ long and up to $600 \mu \mathrm{A}$ pulses. Neurons without a response at minimum stimulation or with ePSP amplitudes smaller than $0.5 \mathrm{mV}$ were excluded.

For the repetitive stimulation protocols, we used frequencies that are comparable to those recorded in vivo (Boccara et al., 2010). Analysis was done by investigating in vivo spike trains. PrS and PaS neurons have very variable firing properties in vivo and they spike either sparsely at $1 \mathrm{~Hz}$ or they fire in a spike train of $1-4$ repetitions with a frequency of $10-50 \mathrm{~Hz}$.

Glutamate uncaging experiments. For glutamate uncaging experiments, patch pipettes were pulled from borosilicate capillaries (GC120F10; Harvard Apparatus) with a resistance between 4 and $7 \mathrm{M} \Omega$ containing the following (in $\mathrm{mm}$ ): $135 \mathrm{~K}$-gluconate, 10 HEPES, 2 ATP$\mathrm{Mg}, 0.2 \mathrm{EGTA}, 5$ phosphocreatine, and $20 \mathrm{KCl}$ with $5 \mathrm{mg} / \mathrm{ml}$ biocytin, $\mathrm{pH}$ 7.3. The seal resistance was $>1 \mathrm{G} \Omega$. Recordings were made with an Axopatch 700B Amplifier (Molecular Devices) in bridge mode. Capacitance compensation was maximal and bridge balance adjusted. The signal was lowpass filtered at $2 \mathrm{kHz}$ and acquired at a sampling rate of $5 \mathrm{kHz}$ (National Instruments BNC-2090).

The setup and experimental procedure for photolysis of caged glutamate have been described previously (Bendels et al., 2008; Beed et al., 2010). For photostimulation and data acquisition, we used the Morgentau M1 microscope software (Morgentau Solutions). In brief, 
A Pipette stimulation

PrS stimulation

PaS stimulation
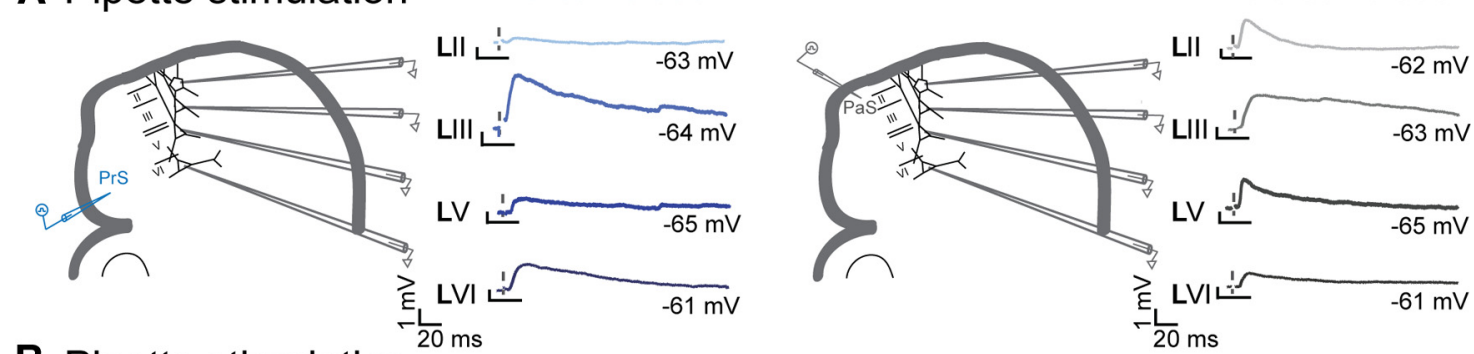

B Pipette stimulation

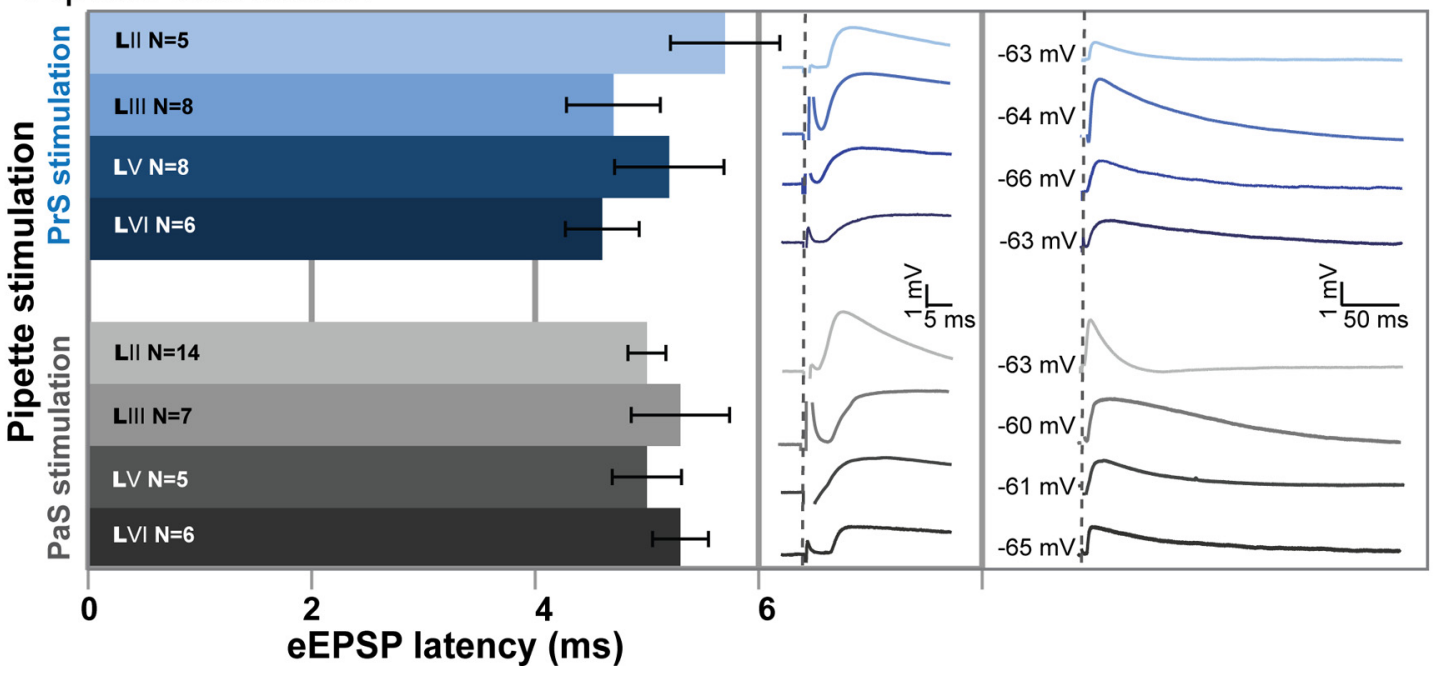

Figure 3. Glass electrode stimulation in PrS (blue) or PaS (gray) evoked responses in principal neurons in all cell layers of MEC. A, Outline of a typical horizontal brain slice with schematic drawings of typical MEC principal neurons in LII, LIII, LV, and LVI (Canto and Witter, 2012) and the position of a stimulation electrode in PrS (left) and PaS (right). Traces to the right of the outlines illustrate a single eEPSP recorded from one LII, one LIII, one LV, and one LVI MEC principal neuron, evoked by stimulating either in PrS or PaS. Dashed vertical lines indicate the moment of stimulation. The average membrane potential of recorded neurons is indicated below each trace. $\boldsymbol{B}$, Averaged eEPSP latencies for principal neurons in layers II, III, V, and VI of MEC following stimulation in either PrS or PaS. The mean \pm SEM latencies of eEPSPs are presented (left) as well as the amplitudes and time courses of average traces of the eEPSPs for all neurons per condition and layer (central and right). All traces in one column have the same units on the $x$ - and $y$-axis (units between PrS and PaS traces). Central traces are a zoom-in of the first 40 ms of the right traces. Dashed vertical lines indicate the moment of stimulation. The average membrane potential of recorded neurons is indicated on the left side of the right traces. All data are based on 50 replications per neuron $(N$, total number of neurons recorded per condition; see Table 1 for holding potentials during recordings).

$20 \mathrm{ml}$ of $200 \mu \mathrm{M}$ 4-methoxy-7-nitroindolinyl-caged-1-glutamate (Tocris Bioscience) were recirculated at $3-5 \mathrm{ml} / \mathrm{min}$. The maximum time period of recirculation was $3 \mathrm{~h}$. The duration of the laser flash was $2 \mathrm{~ms}$; the laser power under the objective, corresponding to the stimulus intensity levels used, was constantly monitored with a photodiode array-based photodetector (PDA-K-60; RappOptoelectronics). The optical system was adapted to achieve an effective light spot diameter of $15 \mathrm{~mm}$ in the focal plane. Generally, stimulation points were defined in a hexagonal grid with a raster size of $30 \mathrm{~mm}$. For all experiments, the focal depth of the uncaging spot was set at $50 \mathrm{~mm}$ below the slice surface.

\section{Data analysis and statistics used}

VSD experiments. Optical signals were analyzed off-line using BrainVision analysis software. Changes in membrane potential were evaluated as fractional changes of fluorescence $(\Delta F / F)$. Each pixel of the image sensor records the sum of the membrane potential changes of every membranous structure projected onto the pixel. Thus, fluctuations of the optical signal from baseline represent the sum of membrane potential changes. Assuming that in all instances the contribution of glial cells to the signal will be constant, we calculated the integrals of the curves as this measure represents the size of total membrane potential changes associated with neural activity (Grinvald et al., 1988). These measures, obtained using BrainVision analysis software (Koganezawa et al., 2008), were compared in the different stimulation protocols.

Single-neuron recordings. Analysis of membrane properties of single neurons was done as previously reported (Canto and Witter, 2012) using custom-made procedures in Igor Pro Software (Wavemetrics). Synaptic events induced by extracellular stimulation were analyzed by taking an average trace of 50 sweeps of intracellular membrane potential changes in response to $\mathrm{PrS}$ and $\mathrm{PaS}$ stimulation, and rise and decay times were derived by fitting two decaying exponential functions to the evoked EPSPs (eEPSPs), starting at the beginning of the event. The slope of the onset was measured as the rise of the amplitude in millivolts per milliseconds for the first $2 \mathrm{~ms}$ after the onset of the response. The EPSP latency was measured from the beginning of the stimulus artifact to the EPSP start. The EPSP amplitude was calculated by measuring the distance between the EPSP threshold and the maximum voltage deflection. Neurons were selected with a resting membrane potential of lower than $-50 \mathrm{mV}$.

Statistical analysis. Normality of the data was tested with Levene's test and subsequently univariate ANOVA followed by post hoc Bonferroni tests were used to test differences in characteristics between layers or stimulation electrodes. If assumptions for a parametric test were not met (Levene's test $p<0.05$ ), Kruskal-Wallis followed by Mann-Whitney $U$ tests were used. We applied a Bonferroni correction to adjust for multiple comparisons. To analyze the changes in the eEPSP amplitude within a train of four stimulations at different frequencies with different stimulation electrodes, a repeated measures analysis was used followed by paired $t$ tests. For the repeated-measures analysis the first eEPSP amplitude was used as a covariate. We used a Bonferroni correction to adjust for multiple comparisons. If assumptions for sphericity were not met (Mauchly's test $p<0.05$ ), Greenhouse-Geisser correction values were used to test for significance.

Glutamate uncaging experiments. For detection of synaptic events, we used the automatic detection method described by (Bendels et al., 2008). 
Table 1. Properties of the membrane and the eEPSPs elicited in different MEC cell layers

\begin{tabular}{|c|c|c|c|c|c|c|c|c|c|}
\hline & $\begin{array}{l}\text { Amplitude } \\
0.9 \mathrm{mV}\end{array}$ & $\begin{array}{l}\text { Failure rate } \\
0.9 \mathrm{mV} / 9 \mathrm{mV} \\
(\%)\end{array}$ & $\begin{array}{l}\text { Latency } \\
\text { (ms) }\end{array}$ & Rise time (ms) & $\begin{array}{l}\text { Slope } \\
\mathrm{mV} / \mathrm{ms}\end{array}$ & Decay time (ms) & $\begin{array}{l}\text { Half-width } \\
\text { (ms) }\end{array}$ & $\begin{array}{l}\text { Membrane potential } \\
(\mathrm{mV})\end{array}$ & N \\
\hline \multicolumn{10}{|c|}{ PrS stimulation } \\
\hline LII & $0.68 \pm 0.58$ & $24 / 14$ & $5.3 \pm 0.25$ & $5.61 \pm 0.69$ & $0.16 \pm 0.06$ & $\begin{array}{l}19.30 \pm 9.65 \\
\operatorname{LIII} p=0.005 \\
\operatorname{LV} p=0.0004 \\
\operatorname{LVI} p<0.001\end{array}$ & $\begin{array}{l}26.6 \pm 6.7 \\
\operatorname{LIII} p=0.005 \\
\operatorname{LV} p=0.006 \\
\operatorname{LVI} p<0.001\end{array}$ & $-63.7 \pm 1.31$ & 5 \\
\hline LIII & $2.38 \pm 0.51$ & $6 / 1$ & $5.0 \pm 0.31$ & $\begin{array}{l}3.24 \pm 0.59 \\
\operatorname{LVI} p=0.01\end{array}$ & $0.46 \pm 0.08$ & $68.46 \pm 8.36$ & $60.1 \pm 5.9$ & $-66.8 \pm 1.14$ & 8 \\
\hline LV & $0.80 \pm 0.50$ & $17 / 7$ & $5.3 \pm 0.44$ & $3.92 \pm 0.59$ & $0.21 \pm 0.09$ & $69.60 \pm 7.63$ & $60.0 \pm 5.8$ & $-64.6 \pm 1.14$ & 8 \\
\hline LVI & $0.76 \pm 0.58$ & $24 / 11$ & $5.0 \pm 0.17$ & $5.80 \pm 0.69$ & $0.17 \pm 0.03$ & $92.34 \pm 9.65$ & $76.5 \pm 6.7$ & $-65.5 \pm 1.31$ & 6 \\
\hline \multicolumn{10}{|c|}{ PaS stimulation } \\
\hline LII & $2.62 \pm 0.41$ & $7 / 0$ & $4.6 \pm 0.33$ & $\begin{array}{l}5.61 \pm 0.48 \\
\operatorname{LV} p=0.028 \\
\operatorname{LVI} p=0.013\end{array}$ & $0.62 \pm 0.19$ & $\begin{array}{l}14.41 \pm 7.53 \\
\text { LIII, LV, LVI } \\
\text { all layers } p<0.001\end{array}$ & $\begin{array}{l}\quad 20 \pm 5.6 \\
\text { LIII, LV, LVI } \\
\text { all layers } p<0.001\end{array}$ & $-61.2 \pm 0.85$ & 14 \\
\hline LIII & $1.55 \pm 0.61$ & $4 / 0$ & $5.2 \pm 0.49$ & $4.84 \pm 0.42$ & $0.40 \pm 0.10$ & $85.15 \pm 14.65$ & $79.1 \pm 13.8$ & $-61.8 \pm 1.25$ & 7 \\
\hline LV & $1.00 \pm 0.53$ & $38 / 6$ & $4.7 \pm 0.42$ & $3.24 \pm 0.61$ & $0.26 \pm 0.10$ & $45.28 \pm 9.60$ & $45 \pm 7.1$ & $-62.3 \pm 1.08$ & 5 \\
\hline LVI & $0.82 \pm 0.61$ & $38 / 10$ & $5.7 \pm 0.49$ & $2.75 \pm 0.70$ & $0.25 \pm 0.03$ & $75.98 \pm 11.09$ & $59 \pm 8.2$ & $-65.2 \pm 1.25$ & 6 \\
\hline
\end{tabular}

The columns represent measured parameters of the eEPSPs in different MEC layers (rows; LII-LVI) upon stimulation of PrS (top) and PaS (bottom) with a pipette stimulation electrode. All values represent the mean of all neurons/layer + SEM. Data for each individual neuron entered in the analysis are the means of 50 replications for each condition. Levene's tests to check for homogeneity were performed. If assumptions for parametric tests were met, an ANOVA test followed by post hoc Bonferroni tests was used. If not, Kruskal-Wallis followed by Mann-Whitney $U$ tests was performed. Differences between data points are considered statistically significant at $p<0.05$ for parametric tests and $p<0.0125$ for nonparametric tests after Bonferroni correction. Significant differences between each respective layer with any of the other layers are indicated in each cell by the inserts LII-LVI, respectively, together with the $p$ value. Column description: amplitude $0.9 \mathrm{mV}$, maximum amplitude of the eEPSP after stimulation with $0.9 \mathrm{mV}$; failure rate; the number of instances, represented as percentages, that no eEPSP was elicited out of 50 replications; latency, time in milliseconds measured from the beginning of the stimulation artifact to the onset of the eEPSP; rise time, slope, decay time, and half-width, parameters to characterize the eEPSP waveform; membrane potential, the potential of the membrane at which experiments were performed; $N$, the numbers of neurons measured for this event per cell layer. For $p$ values of individual Bonferroni tests see table. Differences between layers, amplitude; PrS stimulation: $d f 3, \chi^{2} 5.54, p=0.137 ;$ PaS stimulation: $F_{(3,28)}=2.31, p=0.98$; latency: PrS stimulation: Kruskal-Wallis df $3, \chi^{2}$ 5.35 $p=0.148$; PaS stimulation: $F_{(3,28)}=$ $1.71, p=1.88$; rise time: PrS stimulation: $d f 3, \chi^{2} 8.95, p=0.03$; PaS stimulation: $F_{(3,28)}=5.01, p=0.007$; slope: PrS stimulation: $F_{(3 ; 28)}=1.244 p=0.310 ;$ PaS stimulation: $F_{(3 ; 24)}=4.011 p=0.020 ;$ Bonferroni: nonsignificant; decay time differences between layers: PrS stimulation: $F_{(3,24)}=10.25, p<0.001 ;$ PaS stimulation: $d f 3, \chi^{2} 23.68, p<0.001$; half-width: PrS stimulation: $F_{(3,24)}=9.91, p<0.001 ;$ PaS stimulation: $d f 3, \chi^{2}$ 22.34, $p<0.001$; Membrane potential: PrS stimulation: $F_{(3,24)}=1.22, p=0.324 ;$ PaS stimulation: $F_{(3,28)}=2.28, p=0.101$.

Parameters used for automatic detection were based on visual inspection of the raw data. See Bendels et al. (2010) for a detailed description of the algorithm used for the separation of specific events constituting presynaptic inputs from background noise.

\section{Immunohistochemistry}

After recording, slices were fixed in a solution containing $4 \%$ paraformaldehyde (PFA) in $0.125 \mathrm{~mm} \mathrm{~PB}, \mathrm{pH} 7.4$, and stored at $4^{\circ} \mathrm{C}$ for at least $24 \mathrm{~h}$. For neuron visualization the slices were washed overnight in 0.125 mM PB buffer, pH 7.4. Next day, the slices were again washed in PB-TX ( $1 \%$ Triton in $0.125 \mathrm{~mm}$ PB buffer) followed by incubating them in $5 \%$ goat serum in PB-TX for $2-3 \mathrm{~h}$ on a rotator. Afterward the slices were incubated overnight on a rotator in streptavidin conjugated to Alexa 633 (1:300) diluted in 1\% PB-TX. Then the slices were again washed in 0.125 mM PB. Finally the slices were dehydrated through increased concentrations of alcohol and cleared in methyl salicylate (Kononenko and Pflüger, 2007). All neurons were analyzed using a conventional fluorescent microscope (Zeiss M1 and Leica DM R) or a confocal laser-scanning microscope (Zeiss SLM510).

To specify the area of stimulation and recording for VSD experiments, slices were postfixed in $4 \%$ PFA for up to 1 week and subsequently kept in PBS with $30 \%$ sucrose for $>10 \mathrm{~h}$ and cut at $40-50 \mu \mathrm{m}$ thickness using a freezing microtome. Mounted sections were Nissl stained with cresyl violet and covered slipped using Entellan. Digital images of sections were combined with the optical imaging data to identify the region in which changes in neural firing occurred.

\section{Results}

Principal neurons in MEC receive excitatory inputs from PrS and $\mathrm{PaS}$

To characterize the functional interactions of inputs from PrS and $\mathrm{PaS}$ with neurons in all layers of MEC, we initially established that connectivity was preserved in semihorizontal slices from animals in which inputs from PrS or PaS had been fluorescently labeled through injections of an anterogradely transported tracer in superficial layers of $\mathrm{PrS}$ or $\mathrm{PaS}$, i.e., the main origin of these projections to MEC (Honda and Ishizuka, 2004) (Fig. 1; PrS injection, $N=9$ and PaS injection, $N=8$ ). In slices taken from these animals, the place of stimulation was chosen to coincide with the area that showed a high level of fluorescent neurons in either PrS or PaS. Recordings of neurons in MEC were performed in or deep to the area where anterogradely labeled axons were visible. All subsequent experiments were performed in similarly angled slices at corresponding dorsoventral levels, using comparable stimulation and recording positions, to ascertain a high probability of connectivity.

We subsequently validated that these slices maintained sufficient connectivity using VSD imaging. Extracellular stimulation with a tungsten bipolar electrode at a fixed position during the entire experiment (single pulse, $0.6 \mathrm{~mA}$ for $300 \mu \mathrm{s}$ ) resulted in changes in optical signals in all layers, reflecting depolarizing inputs (Fig. $2 A, B$ ). Significant signal changes became apparent in all layers after latencies between 5 and $10 \mathrm{~ms}$. Stimulation in $\operatorname{PrS}$ evoked significantly larger changes in optical signals in layer V (LV) and layer VI (LVI) than in layer II (LII) and layer III (LIII) $(N=12$; degrees of freedom $(d f) 3, \chi^{2} 24.79, p=0.0010$; Fig. $2 B$ shows individual $p$ values). Following $\mathrm{PaS}$ simulation, amplitude changes were present in all layers with those in LII being largest $\left(N=12 ; d f 3, \chi^{2}\right.$ 23.70, $p<0.001$; Fig. $2 B$ shows individual $p$ values).

We next tested with single-cell patch recordings whether principal neurons in all MEC cell layers received inputs from PrS or $\mathrm{PaS}$ and whether evoked response properties are layer specific as suggested by the VSD results. Recorded neurons were classified as principal neurons based on previously established physiological and morphological properties, and the position of the cell soma and its physiological features were used to determine the laminar position (Canto and Witter, 2012). First, we patched two or three MEC neurons in layers II-V in semihorizontal slices simultaneously, while stimulating $\mathrm{PrS}$ or PaS with a bipolar stimulation electrode, similar to the stimulation used in VSD imaging. Such stimulation in $\mathrm{PrS}$ or $\mathrm{PaS}$ resulted in eEPSPs in principal neurons 

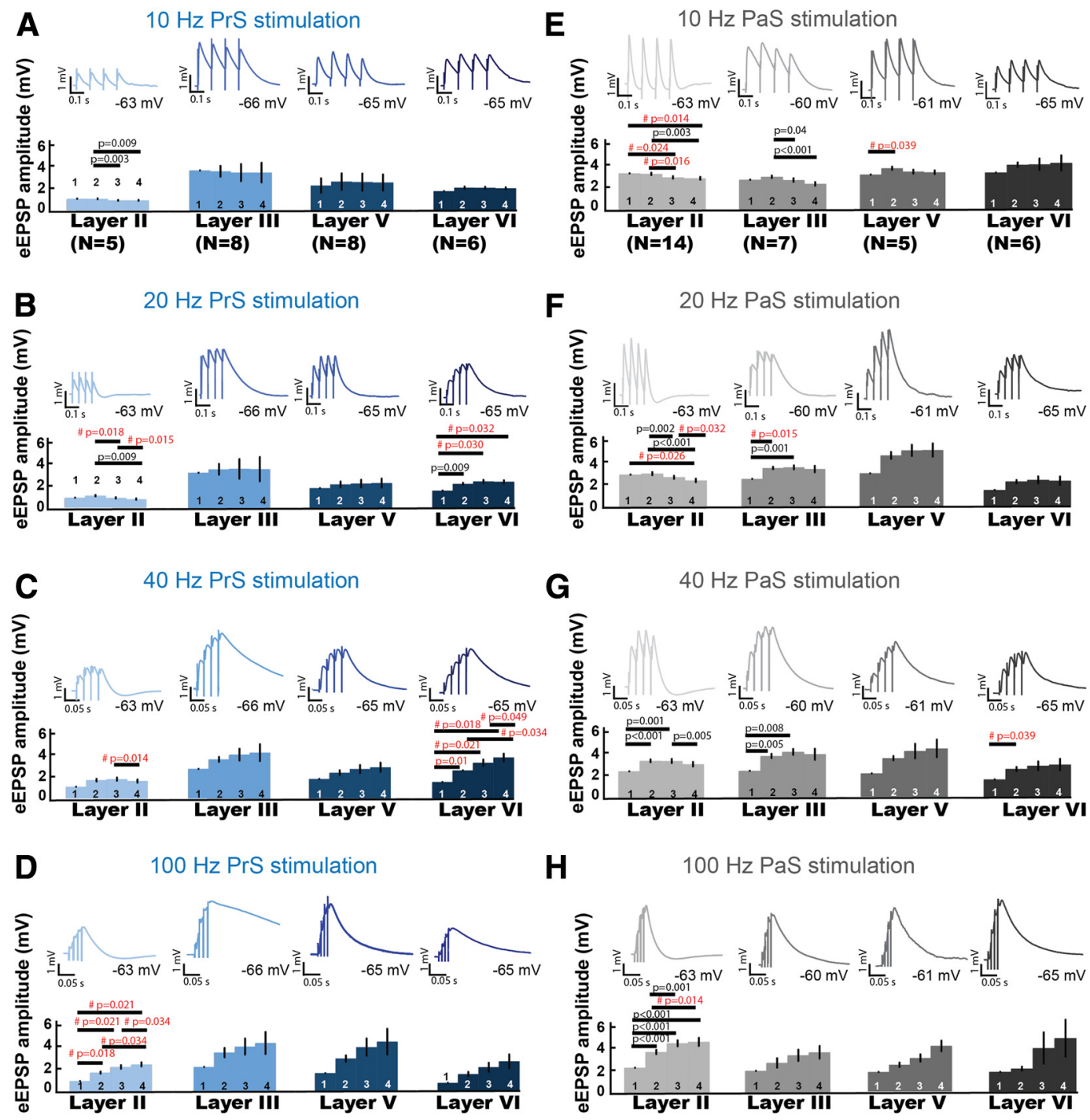

\# not significant after Bonferroni correction $\mathrm{p}<0.05$

Figure 4. eEPSPs show layer-specific frequency-dependent plasticity. $\boldsymbol{A}-\boldsymbol{H}$, eEPSPs following glass electrode stimulation in $\operatorname{PrS}(\boldsymbol{A}-\boldsymbol{D})$ or $\operatorname{PaS}(\boldsymbol{E}-\boldsymbol{H})$ at a stimulation frequency (4 stimuli/train) of $10(\boldsymbol{A}, \boldsymbol{E}), 20(\boldsymbol{B}, \boldsymbol{F}), 40(\boldsymbol{C}, \boldsymbol{G})$, and $100 \mathrm{~Hz}(\boldsymbol{D}, \boldsymbol{H})$. Each top row represents the average trace of all replications $(N=50)$ for all neurons per condition and per layer (number of neurons per layer are indicated in $\boldsymbol{A}$ and $\boldsymbol{E}$ ). Below the individual voltage traces the average membrane potential is indicated. Each bottom row illustrates the average evoked amplitudes for each of the four individual stimuli in each stimulus train. Significant differences are indicated with the corresponding $p$ value. Not significant $p$ values after Bonferroni correction are indicated in red and with \#. A, PrS $10 \mathrm{~Hz}$ stimulation: $\mathrm{LII} F_{(3,12)}=33.52, p<0.001 ; \mathrm{LIII} F_{(1.00,6.04)}=0.41, p=0.547 ; \operatorname{LV} F_{(1.03,6.22)}=0.269, p=0.630 ; \operatorname{LVI} F_{(3,12)}=6.007, p=0.010 . B_{1}$ PrS 20 Hz stimulation: LIIF $F_{(3,12)}=39.406, p<$ $0.001 ; \operatorname{LIII} F_{(1.00,6.12)}=0.20, p=0.601 ; \operatorname{LV} F_{(1.03,6.22)}=4.665, p=0.074 ; \operatorname{LVI} F_{(1.231,4.923)}=22.57, p=0.005$. C, PrS 40 Hz stimulation: LII $F_{(1.028,3.084)}=12.648, p=0.036 ; \mathrm{LIII} F_{(1.007,6.042)}=$ $3.13, p=0.137 ; \operatorname{LV} F_{(1.0097,6.58)}=10.13, p=0.045 ; \operatorname{LVI} F_{(1.553,6.21)}=6.70, p=0.032 . D, \operatorname{PrS} 100 \mathrm{~Hz}$ stimulation: $\operatorname{Lll} F_{(3,12)}=2.48, p=0.016 ; \mathrm{LIII} F_{(1.00,6.12)}=0.20, p=0.237 ; \mathrm{LV} F_{(1.03,6.22)}=$ $3.194, p=0.147 ; \operatorname{LVI} F_{(1.019,3.058)}=0.843, p=0.130 . E$, PaS 10 Hzstimulation: Lll $F_{(2.035,24.42)}=14.60, p<0.001 ; \operatorname{LIII} F_{(3,15)}=4.907, p=0.014 ; \mathrm{LV} F_{(3,21)}=3.458, p=0.035 ; \mathrm{LVI} F_{(1.025,4.102)}=0.026$, $p=0.994 . F$, PaS 20 Hz stimulation: Lll $F_{(2.035,24.42)}=14.60, p=0.002 ;$ LIII $F_{(1.34,8.04)}=6.82, p=0.049 ; \operatorname{LV} F_{(1.055,6.33)}=4.194, p=0.083 ; \operatorname{LVI} F_{(1.013,4.052)}=0.417, p=0.744 . G$, PaS 40 Hzstimulation: $\mathrm{LIIF} F_{(1.538,18.45)}=12.88, p=0.0016 ; \mathrm{LIII} F_{(3,12)}=17.73, p<0.001 ; \operatorname{LV} F_{(1.04,4.16)}=1.08, p=0.358 ; \mathrm{LVI} F_{(1.388,6.942)}=7.503, p=0.024 . \mathrm{H}$, PaS 100 Hz stimulation: Lll $F_{(2.035,24.42)}=14.60, p=0.0016 ; \mathrm{LIII}$ $\left.F_{(1.34,8.04)}=4.67, p=0.367 ; \operatorname{LV} F_{(3,21)}=6.518, p=0.012 ; \operatorname{LVI} F_{(1.096,4.386)}=0.568, p=0.505\right)$.

in layers II-V, all showing comparable short latencies (PrS stimulation: LII $N=5,4.2 \pm 0.3 \mathrm{~ms}$; LIII $N=10,4.7 \pm 0.3 \mathrm{~ms}$ LV $N=10,4.3 \pm 0.3 \mathrm{~ms} ; \mathrm{PaS}$ stimulation: $\mathrm{LII} N=5,3.8 \pm 0.5 \mathrm{~ms}$; LIII $N=6,4.8 \pm 0.6 \mathrm{~ms}$; LV $N=6,4.2 \pm 0.4 \mathrm{~ms}$ ). Latencies did not differ significantly between layers and stimulation areas (latency differences between layers: $\operatorname{PrS}$ stimulation, $F_{(2,22)}=0.73$, $p=0.492 ; \mathrm{PaS}$ stimulation, $F_{(2,14)}=1.03, p=0.383$; latency differences between stimulation areas: $\left.F_{(1,40)}=1.119, p=0.732\right)$.

Bipolar stimulation activates a substantial volume of tissue and thus likely activates a large number of input neurons to MEC. Also, in view of the restricted size and close apposition of both PrS and $\mathrm{PaS}$, spread of current from one into the other or into MEC might have occurred. Stimulation with a glass electrode with a 1 $\mu \mathrm{m}$ pipette tip, which stimulates a smaller volume of tissue and thus a lower number of neurons compared with bipolar stimulation, clearly showed that principal cells in all layers respond to stimulation in either PrS or PaS (Fig. 3A,B; Table 1).

To compare between ePSPs of principal neurons in different layers, in different slices, and using different stimulation frequencies, we recorded from principal neurons while keeping membrane potentials in all layers and situations the same [Table 1; membrane potential differences between layers: PrS stimulation $(\mathrm{LII} N=5$; LIII $N=8 ; \operatorname{LV} N=8 ; \operatorname{LVI} N=6), F_{(3,23)}=1.22, p=$ 0.324 ; PaS stimulation (LII $N=14$; LIII $N=7 ; \mathrm{LV} N=5$; LVI 
Table 2. Decay time and afterhyperpolarizing events following the last eEPSP

\begin{tabular}{|c|c|c|c|c|c|}
\hline & Decay time $10 \mathrm{~Hz}$ (ms) & Decay time $20 \mathrm{~Hz}$ (ms) & Decay time $40 \mathrm{~Hz}$ (ms) & Decay time $100 \mathrm{~Hz}$ (ms) & $N$ \\
\hline \multicolumn{6}{|c|}{ PrS stimulation } \\
\hline \multirow[t]{4}{*}{ LII } & $37.60 \pm 6.99$ & $29.02 \pm 3.46$ & $32.55 \pm 3.9$ & $28.20 \pm 3.81$ & 5 \\
\hline & LIIII $p=0.002$ & LIII $p<0.001$ & LIII $p<0.001$ & LIII $p=0.003$ & \\
\hline & $\operatorname{LVI} p=0.004$ & $\operatorname{LV} p=0.012$ & $\mathrm{LV} p=0.004$ & $\operatorname{LV} p=0.02$ & \\
\hline & & $\operatorname{LVI} p=0.004$ & $\operatorname{LVI} p=0.004$ & & \\
\hline \multirow[t]{2}{*}{ LIIII } & $95.63 \pm 14.37$ & $158.35 \pm 34.30$ & $204.55 \pm 59.92$ & $208.62 \pm 76.58$ & 8 \\
\hline & & $\operatorname{LV} p=0.005$ & & & \\
\hline LV & $58.43 \pm 6.47$ & $50.21 \pm 8.12$ & $71.97 \pm 12.43$ & $67.4 \pm 8.49$ & 8 \\
\hline \multirow[t]{2}{*}{ LVI } & $157.89 \pm 44.68$ & $97.48 \pm 19.12$ & $109.84 \pm 15.60$ & $101.97 \pm 21.76$ & 6 \\
\hline & Hy Amp $10 \mathrm{~Hz}(\mathrm{mV})$ & Hy Amp $20 \mathrm{~Hz}(\mathrm{mV})$ & Hy Amp $40 \mathrm{~Hz}(\mathrm{mV})$ & Hy Amp $100 \mathrm{~Hz}$ (mV) & $N$ \\
\hline \multirow[t]{4}{*}{ LII } & $0.17 \pm 0.0609$ & $0.255 \pm 0.154$ & $0.31 \pm 0.21$ & $0.38 \pm 0.23$ & 5 \\
\hline & $\mathrm{LIII} p=0.003$ & LIII $p=0.011$ & LIIII $p<0.001$ & LIII, LV, LVI & \\
\hline & $\operatorname{LV} p<0.001$ & $\mathrm{LV} p=0.003$ & $\operatorname{LV} p=0.009$ & all layers $p<0.001$ & \\
\hline & LVI $p<0.001$ & $\operatorname{LVI} p=0.003$ & $\operatorname{LVI} p=0.009$ & & \\
\hline LIII & $0.063 \pm 0.029$ & $0.041 \pm 0.021$ & $0.01 \pm 0.01$ & 0 & 8 \\
\hline LV & 0 & 0 & 0 & 0 & 8 \\
\hline LVI & 0 & 0 & 0 & 0 & 6 \\
\hline \multicolumn{6}{|c|}{ PaS stimulation } \\
\hline \multirow[t]{4}{*}{ LII } & $30.52 \pm 2.15$ & $26.25 \pm 4.22$ & $24.80 \pm 2.12$ & $17.10 \pm 2.82$ & 14 \\
\hline & LIIII $p<0.001$ & LIII $p<0.001$ & LIIII $p<0.001$ & LIII $p<0.001$ & \\
\hline & $\operatorname{LV} p=0.001$ & $\operatorname{LV} p<0.001$ & $\operatorname{LV} p<0.001$ & $\operatorname{LV} p=0.004$ & \\
\hline & $\operatorname{LVI} p<0.001$ & $\operatorname{LVI} p=0.001$ & $\operatorname{LVI} p=0.002$ & $\mathrm{LV} p<0.001$ & \\
\hline LIII & $88.21 \pm 16.17$ & $106.67 \pm 15.47$ & $104.68 \pm 23.85$ & $120.21 \pm 24.90$ & 7 \\
\hline LV & $93.97 \pm 33.86$ & $74.79 \pm 10.91$ & $85.34 \pm 7.73$ & $55.55 \pm 3.71$ & 5 \\
\hline \multirow[t]{2}{*}{ LVI } & $103.08 \pm 15.68$ & $87.44 \pm 17.17$ & $72.64 \pm 19.25$ & $66.95 \pm 10.3$ & 6 \\
\hline & Hy Amp $10 \mathrm{~Hz}(\mathrm{mV})$ & Hy Amp $20 \mathrm{~Hz}$ (mV) & Hy Amp $40 \mathrm{~Hz}$ (mV) & Hy Amp $100 \mathrm{~Hz}(\mathrm{mV})$ & $N$ \\
\hline \multirow[t]{4}{*}{ LII } & $0.34 \pm 0.059$ & $0.443 \pm 0.07$ & $0.719 \pm 0.099$ & $0.43 \pm 0.08$ & 14 \\
\hline & LIIII $p=0.009$ & $\operatorname{LV} p<0.001$ & LIIII $p=0.03$ & LIII, LV, LVI & \\
\hline & $\operatorname{LV} p=0.001$ & $\operatorname{LVI} p=0.001$ & $\operatorname{LV} p<0.001$ & all layers $p<0.001$ & \\
\hline & $\mathrm{LVI} p<0.001$ & & $\operatorname{LVI} p<0.001$ & & \\
\hline LIII & $0.089 \pm 0.082$ & $0.281 \pm 0.124$ & $0.066 \pm 0.199$ & 0 & 7 \\
\hline LV & 0 & 0 & 0 & 0 & 5 \\
\hline LVI & 0 & 0 & 0 & 0 & 6 \\
\hline LVI & 0 & 0 & 0 & 0 & 6 \\
\hline
\end{tabular}

The columns of the table represent the decay times and afterhyperpolarization events (Hy Amp) following the last eEPSP in different layers of MEC (rows; LII-LVI) upon repetitive stimulation of PrS (top) and PaS (bottom) with a pipette stimulation electrode at different frequencies (columns). All values represent the mean of all neurons/layer \pm SEM. Data for each individual neuron entered in the analysis are the means of 50 replications for each condition. Levene's tests to check for homogeneity were performed. For all parameters tested, assumptions for parametric tests were not met and Kruskal-Wallis followed by Mann-Whitney $U$ tests were performed. Differences between data points are considered statistically significant at $p<0.0125$ after Bonferroni correction. Significant differences between each respective layer with any of the other layers are indicated in each cell by the inserts LII-LVI, respectively, together with the $p$ value. $N$, the numbers of neurons measured per cell layer. For $p$ values of individual Mann-Whitney $U$ tests see table. Decay time: PrS stimulation: $10 \mathrm{~Hz} d f 3, \chi^{2} 16.32, p=0.001 ; 20 \mathrm{~Hz} d f 3, \chi^{2} 16.66, p=0.001 ; 40 \mathrm{~Hz}$ df $3, \chi^{2} 14.80, p=0.002 ;$ $100 \mathrm{~Hz}$ df $3, \chi^{2} 14.83, p=0.002$. PaS stimulation: $10 \mathrm{~Hz}$ df $3, \chi^{2} 22.59, p<0.001 ; 20 \mathrm{~Hz}$ df $3, \chi^{2} 23.40, p<0.001 ; 40 \mathrm{~Hz}$ df $3, \chi^{2} 19.18, p<0.001 ; 100 \mathrm{~Hz}$ df $3, \chi^{2} 20.61, p<0.001 ;$ Figure 4. Rebound amplitude: PrS stimulation: 10 Hz $d f 3, \chi^{2} 14.47, p=0.007 ; 20 \mathrm{~Hz} d f 3, \chi^{2} 16.62, p=0.001 ; 40 \mathrm{~Hz} d f 3, \chi^{2} 11.18, p=0.0011 ; 100 \mathrm{~Hz} d f 3, \chi^{2} 10.60, p=0.014$. PaS stimulation: $10 \mathrm{~Hz} d f 3, \chi^{2} 20.31, p<0.001 ; 20 \mathrm{~Hz} d f 3, \chi^{2} 23.39, p<0.001 ; 40 \mathrm{~Hz} d f 3, \chi^{2} 21.38, p<$ $0.001 ; 100 \mathrm{~Hz} d f 3, \chi^{2} 23.83, p<0.001$.

$\left.N=6), F_{(3,28)}=2.28, p=0.101\right]$. Also, for each experiment the stimulation electrode was not moved, to assure that recorded responses in different neurons were evoked from the same stimulation site. With the exception of four principal neurons in LII and LIII, which showed inhibitory PSPs (van Haeften et al., 1997), stimulation of either PrS or PaS resulted in eEPSPs in all recorded principal neurons regardless of their laminar position (Fig. $3 A, B$ ). The latencies between time of stimulation, as measured by time between the stimulus artifact and the onset of the eEPSP, in all layers varied between 4.2 and $6.9 \mathrm{~ms}$ (Fig. 3B; PrS stimulation: LII $5.3 \pm 0.25$; LIII $5.0 \pm 0.31$; LV $5.3 \pm 0.44$; LVI $5.0 \pm 0.17$; PaS stimulation: LII $4.6 \pm 0.33$; LIII $5.2 \pm 0.49 ; \mathrm{LV}$ $4.7 \pm 0.42 ; \mathrm{LVI}, 5.7 \pm 0.49)$. Latencies did not differ significantly between layers and stimulation areas (Table 1; latency differences between layers: $\operatorname{PrS}$ stimulation, $d f 3, \chi^{2} 5.35, p=0.148$; $\mathrm{PaS}$ stimulation, $F_{(3,28)}=1.71, p=0.188$; latency differences between stimulation areas: $\left.d f 1, \chi^{2} 0.161, p=0.689\right)$. In all layers we occasionally recorded eEPSPs with a latency $>7 \mathrm{~ms}$, likely reflecting disynaptic activation.
To relate these findings to entorhinal-hippocampal circuitry, we specifically studied the physiological responses of retrogradely labeled LII and LIII hippocampal projection neurons $(N=18$ from 8 rats; Fig. 1A). We found contacts between $\mathrm{PrS}$ and retrogradely labeled projection neurons in LII $(N=4$; latency $5.4 \pm$ $0.4 \mathrm{~ms})$ and $\operatorname{LIII}(N=7$; latency $5.0 \pm 0.03 \mathrm{~ms})$, as well as between $\mathrm{PaS}$ and projection neurons in $\mathrm{LII}(N=10$; latency $4.2 \pm 0.5 \mathrm{~ms})$ and LIII $(N=5$; latency, $4.0 \pm 1 \mathrm{~ms})$. The eEPSP latencies and elicited waveforms were comparable to those observed for the unidentified principal neurons in LII and LIII.

\section{MEC principal neurons show layer-specific differences in synaptic integration}

Waveforms of eEPSPs in principal neurons in different MEC layers after single $\mathrm{PrS}$ and $\mathrm{PaS}$ stimulation were dissimilar (Fig. $3 A, B)$. Differences in the synaptic waveform can influence the temporal integration properties of neurons and thus contribute to the overall laminar response differences upon stimulation (Garden et al., 2008). We first analyzed underlying response 
A

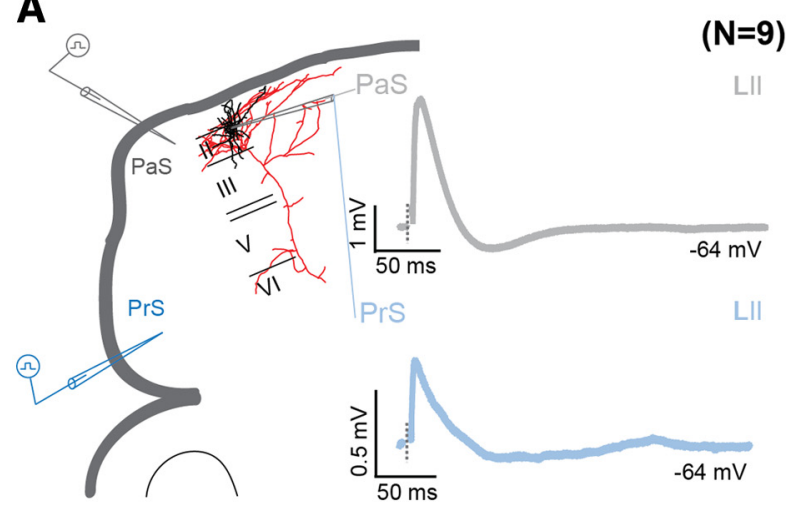

C

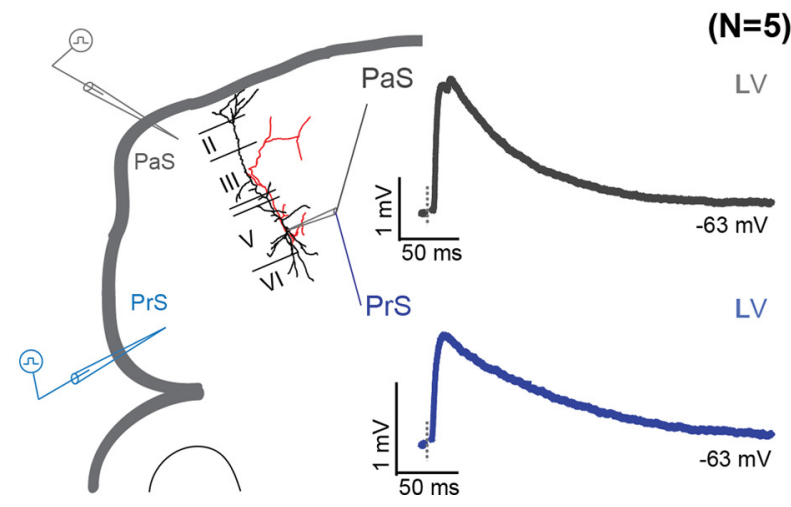

B

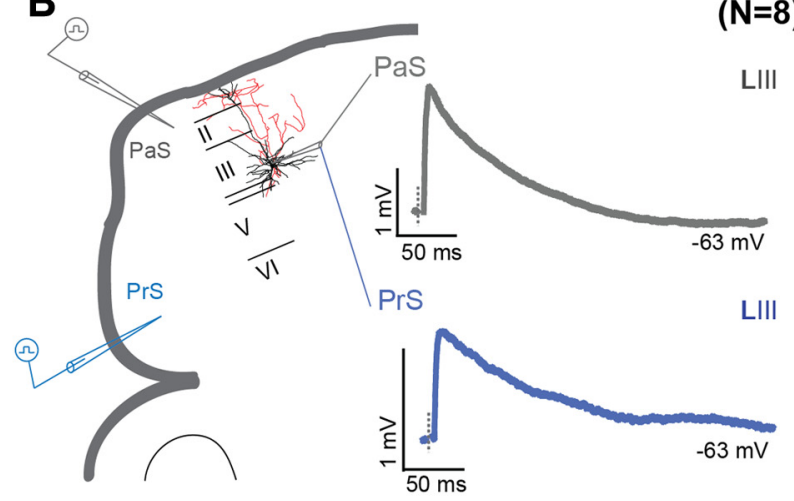

$(\mathrm{N}=8)$

III

D

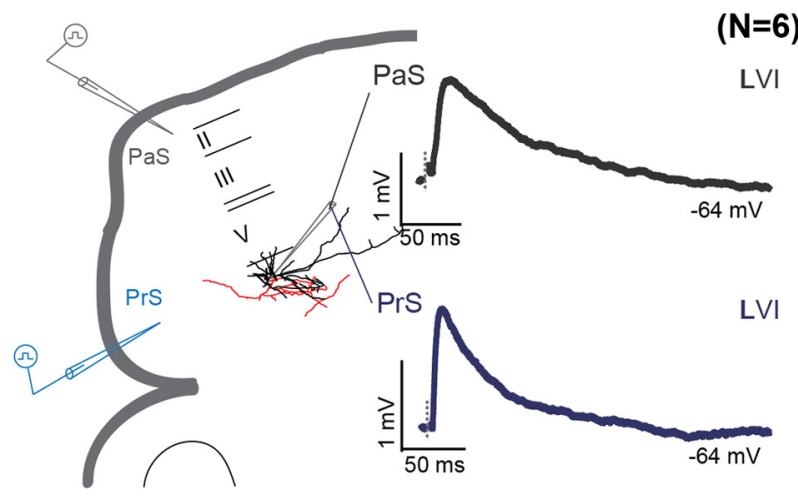

Figure 5. Convergence of inputs from PrS and PaS onto single neurons in layers II, III, V, and VI of MEC. $A-D$, Shows a representative example of a recorded neuron with the dendrites in black and axon in red, and its position in a schematic outline of a (para)hippocampal brain slice (left). Next to the outline of the brain slice, eEPSPs (right) are presented following glass electrode stimulation in PaS (top, gray trace) and PrS (bottom, blue trace). Dashed vertical lines indicate the moment of stimulation. Traces are averages of 50 replications. Below each voltage trace the average membrane potential of the recorded neuron is indicated. $N$, total number of recorded neurons per layer.

properties in more detail. The eEPSPs of LII stellate cells had significantly shorter decay times $(<40 \%)$ and smaller half-widths $(<50 \%)$ compared with principal neurons in all other MEC layers regardless of the site of stimulation in either PrS or PaS (Table 1) $[\operatorname{PrS}$ stimulation (LII $N=5 ; \operatorname{LIII} N=8 ; \operatorname{LV} N=8 ; \operatorname{LVI} N=6$ ), decay time differences between layers: $F_{(3,24)}=10.25, p<0.001$; half-width differences between layers: $F_{(3,24)}=9.91, p<0.001$; $\mathrm{PaS}$ stimulation (LII $N=14$; LIII $N=7$; LV $N=5$; LVI $N=6$ ), decay time differences between layers: $d f 3, \chi^{2} 23.68, p<0.001$; half-width differences between layers: $d f 3, \chi^{2} 22.34, p=0.000$; for individual $p$ values see Table 1]. Only subtle differences between layers were observed in the rise time and no differences were present in the slope of the waveforms (Table 1).

Second, we tested the frequency dependence of the responses by recording eEPSPs using repetitive stimulation $(10,20,40$, and $100 \mathrm{~Hz}$ ) of PrS (LII $N=5$; LIII $N=8 ; \operatorname{LV} N=8 ; \operatorname{LVI} N=6$ ) and PaS (LII $N=14$; LIII $N=7$; LV $N=5$; LVI $N=6$; Fig. 4; Table 2). Principal neurons in different layers showed differences in frequency-dependent facilitation properties and frequencydependent decay times after the last eEPSP, regardless of the site of stimulation. Significant differences were observed between stellate cells in LII compared with principal cells in deep entorhinal layers in that the former showed a significant frequencydependent depression of the responses at both 10 and $20 \mathrm{~Hz}$ stimulation, not present in neurons in deep entorhinal layers (Fig. $4 A, B, E, F)$. Neurons in LIII also showed depressing amplitudes at $10 \mathrm{~Hz}$ stimulation, whereas $20 \mathrm{~Hz}$ stimulation induces slight facilitation, especially in response to $\mathrm{PaS}$ stimulation. Stimulation at higher frequencies resulted in overall facilitation of the responses in all layers (Fig. $4 C, D, G, H$ ). We further observed a faster decay time after the last eEPSP in LII stellate neurons, regardless of stimulation frequency or site (Figs. 3, 4; decay time differences after last eEPSP between layers: PrS stimulation, $d f 3$, 10 and $20 \mathrm{~Hz} p=0.001,40$ and $100 \mathrm{~Hz} p=0.002$; PaS stimulation, $d f 3$, all frequencies $p<0.001$; for individual $\chi^{2}$ and $p$ values; Table 2) and a rebound event after the fast decay that kept the membrane hyperpolarized for several milliseconds before depolarizing back to baseline (Fig. 4; rebound differences after last eEPSP between layers: $\mathrm{PrS}$ stimulation, $d f 3 ; 10 \mathrm{~Hz} p=0.007,20$ $\mathrm{Hz} p=0.001,40 \mathrm{~Hz} p=0.0011,100 \mathrm{~Hz} p=0.014$; PaS stimulation, $d f 3$, all frequencies $p<0.001$; for individual $\chi^{2}$ and $p$ values; Table 2). This implies that principal cells in LII differ from those in LIII-VI in how inputs are integrated.

\section{Principal neurons in all cell layers receive convergent inputs from superficial PrS and PaS}

In view of the high incidence of neurons in all layers of MEC receiving input from either $\mathrm{PrS}$ or $\mathrm{PaS}$ and the dendritic distribution of individual neurons, we next tested in a new series of experiments whether single neurons received convergent inputs from both sources (Fig. 5). In LII, five of five randomly selected stellate cells responded to single pipette stimulation in both PrS and $\mathrm{PaS}$ (latency: $\mathrm{PrS}$ stimulation, $0.53 \pm 0.05$; PaS stimulation, $0.49 \pm 0.06$; Fig. $5 A$ ). In LIII, all four recorded pyramidal neurons 
A
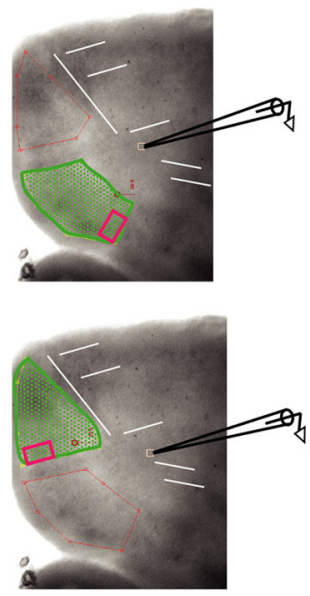

B

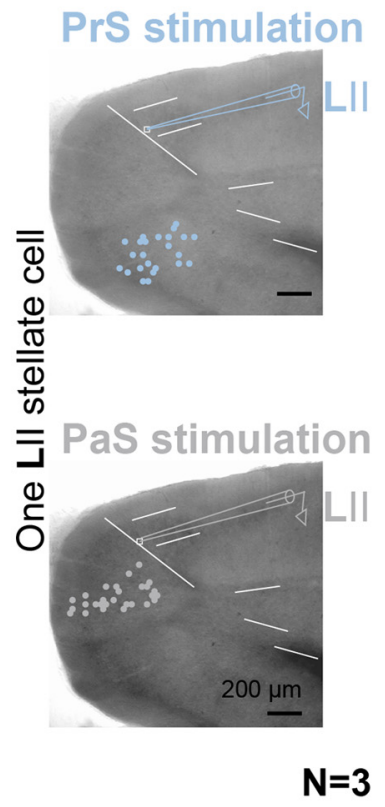

C

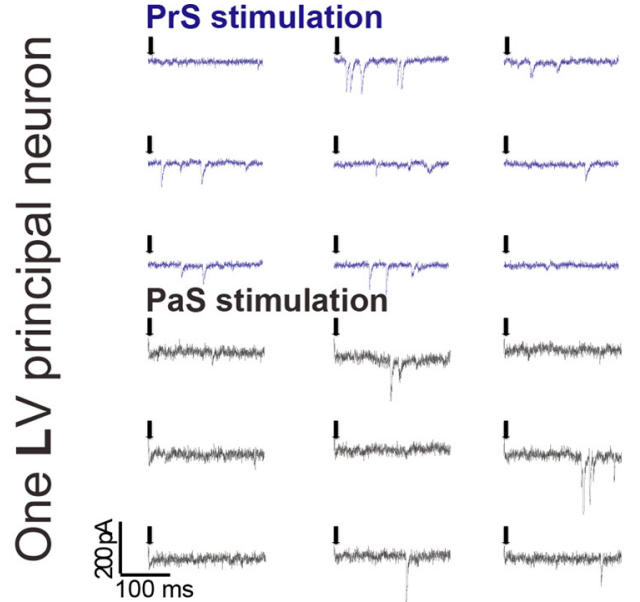

D

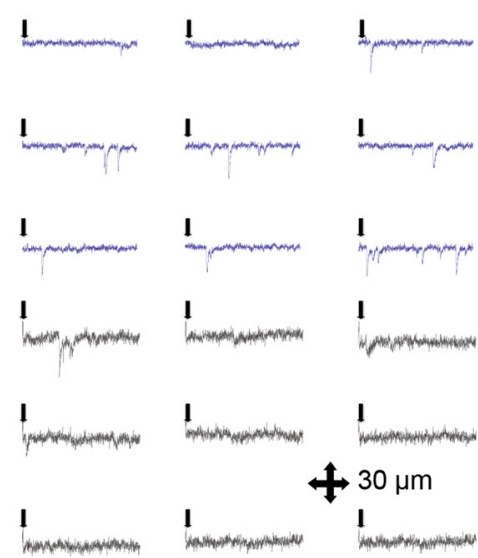

E
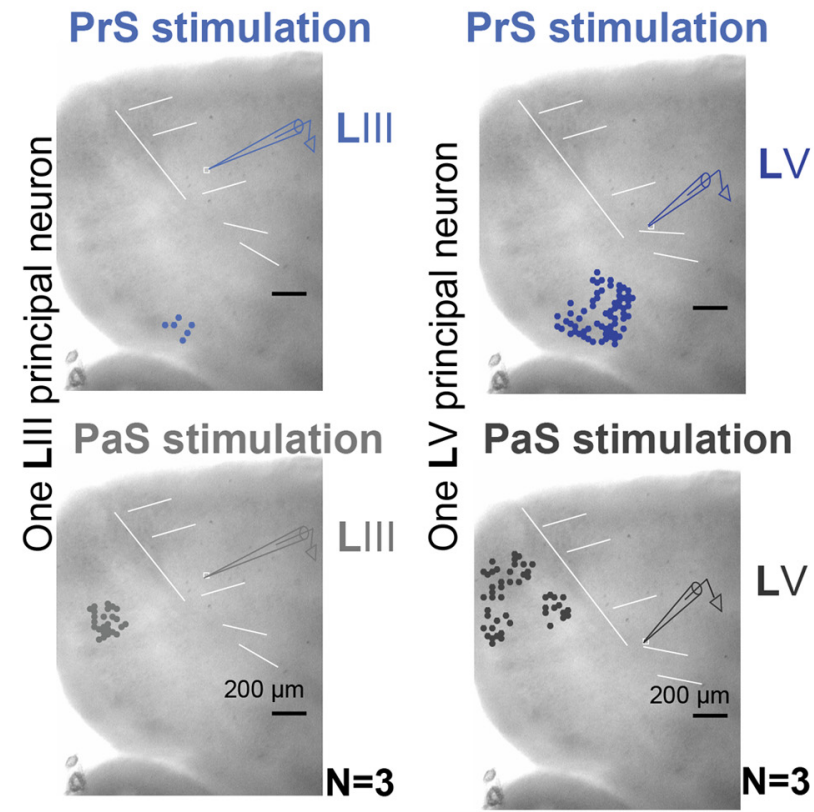

PrS stimulation

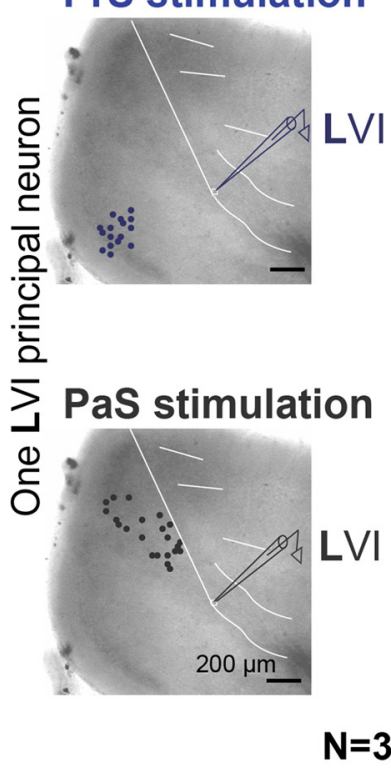

Figure 6. Glutamate uncaging showed that direct excitatory stimulation of neurons in PrS and PaS activates principal neurons in all MEC cell layers and that both inputs converge onto single neurons. $\boldsymbol{A}$, Left, $\boldsymbol{B}-\boldsymbol{E}$, DIC images taken from parts of semihorizontal brain slices showing MEC, PrS, and PaS. $\boldsymbol{A}$, Left, DIC image with the stimulation raster (green dots) superimposed on the PrS (top) and PaS (bottom). The raster essentially covered either PrS or PaS and consisted of points with $30 \mu \mathrm{m}$ spacing. The pink inset indicates the area that resulted in evoked responses in the recorded neuron. $A$, Right, Responses recorded in a selected $L V$ neuron induced by stimulation of the 18 points that are located in the pink highlighted raster in the left figure. For 18 traces, the first $250 \mathrm{~ms}$ after the UV flash are plotted in response to PrS (top, blue) and PaS (bottom, gray) stimulation. The superimposed drawn pipette $(\boldsymbol{A}-\boldsymbol{E})$ indicates the place where the MEC principal neuron was patched in $\mathrm{LV}(\boldsymbol{A}, \boldsymbol{D}), \mathrm{LII}(\boldsymbol{B}), \mathrm{LIII}(\boldsymbol{C})$, and $\mathrm{LVI}(\boldsymbol{E}) \cdot \boldsymbol{B}-\boldsymbol{E}$, DIC images with all points superimposed in the stimulation raster, which upon stimulation, led to a response in the recorded neuron. Each shows the result of a representative neuron responding to both PrS and PaS stimulation. $N$, total number of recorded neurons per layer and stimulation area.

responded to both inputs (latency PrS stimulation, $0.55 \pm 0.08$; $\mathrm{PaS}$ stimulation, $0.59 \pm 0.06$; Fig. $5 B$ ). Retrogradely identified hippocampal projection neurons in MEC LII (latency PrS stimulation, $0.54 \pm 0.05 ; \mathrm{PaS}$ stimulation, $0.43 \pm 0.08 ; N=4$; Fig. $1 \mathrm{~A}$ ) and LIII (latency PrS stimulation, $0.47 \pm 0.033$; PaS stimulation, $0.48 \pm 0.18 ; N=4$ ) also received convergent inputs from both $\mathrm{PrS}$ and PaS. This held true also for all principal neurons recorded from in LV (latency PrS stimulation, $0.56 \pm 0.06$; PaS stimulation, $0.52 \pm 0.03 ; N=5$; Fig. $5 C$ ) and LVI (latency PrS stimulation, $0.51 \pm 0.03$; PaS stimulation, $0.54 \pm 0.04 ; N=6$; Fig. $5 D$ ). All responses showed latencies similar to those in the first set of experiments (latency differences between experiments: PrS stimulation, $d f 6, \chi^{2} 3.33, p=0.766$; PaS stimulation, $F_{(7,44)}=1.299$, $p=0.271)$.

\section{Recorded responses are monosynaptic and originate in PrS} and $\mathrm{PaS}$

The observed latencies (4.2-6.9 ms; Fig. 3B) and the minimal jitter in the onset of the response of neurons (jitter $<700 \mu \mathrm{s}$ ) indicate that the observed membrane potential changes were caused by monosynaptic activation. Additionally, neurons followed $100 \mathrm{~Hz}$ stimulation (Fig. 4D,H) and they responded to minimum stimulation of $0.9 \mathrm{mV}$ with an eEPSP with a relatively low failure rate (Table 1), which also points to monosynaptic, and not polysynaptic activation (González-Burgos et al., 2000; Tolner et al., 2007). These observations also made antidromic stimulation as a cause for responses unlikely, which is in line with the extreme sparseness of MEC projections to layers II and III of PrS and PaS (Köhler, 1986; Kerr et al., 2007). 


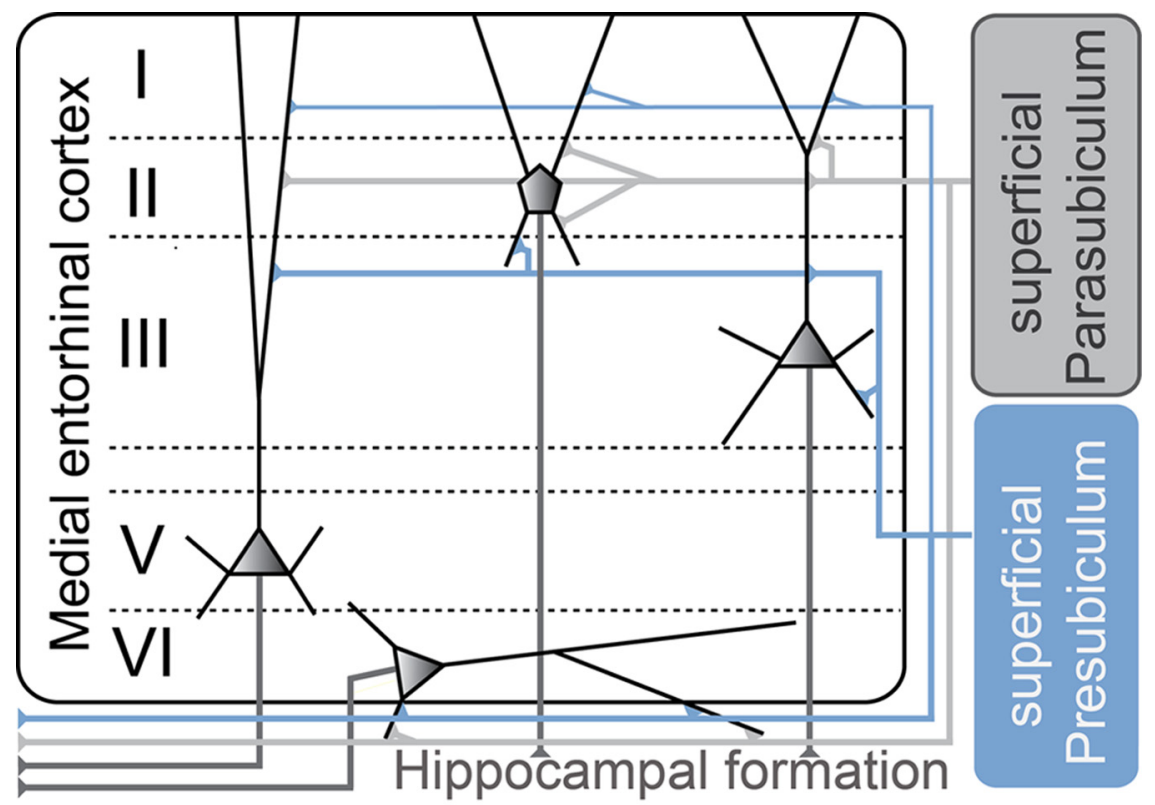

Figure 7. Schematic summary of wiring diagram of MEC. Principal neurons in LII, LIII, LV, and LVI receive convergent monosynaptic inputs from both PrS (blue) and PaS (gray). Lll stellate cells likely receive PaS inputs on proximal dendritic domains, whereas PrS inputs terminate more distally. Among the targeted principal cells are neurons that project to the hippocampal formation. LIII principal neurons likely receive PaS inputs onto their apical dendrites, whereas PrS inputs target the dendritic tuft in LI as well as the basal dendrites in LIII. Among the targeted principal cells are neurons that project to the hippocampal formation. LV principal neurons receive both PaS and PrS inputs most likely on their apical tufts. LVI principal neurons receive both PrS and PaS inputs on unidentified dendrites within LVI. The identity of LV and LVI neurons in terms of their projections has not been established yet.

To control for the possible confound of passing fiber stimulation, either orthodromic or antidromic, we used photostimulation with caged glutamate. Focal uncaging of glutamate in $\operatorname{PrS}$ or $\mathrm{PaS}$ will result in activation of only neurons present at the site of stimulation. We measured synaptic inputs in neurons in all layers of MEC resulting from direct activation of neurons in PrS and $\mathrm{PaS}$ following ultraviolet (UV) photolysis. UV stimulations in either PrS or PaS resulted in clearly detectable eEPSPs, different from baseline, in neurons in LII $(N=3)$, LIII $(N=3), \operatorname{LV}(N=$ $3)$, and LVI ( $N=3$; Fig. 6). In all neurons, we consistently observed eEPSPs upon UV stimulation in either PrS or PaS, indicating that all of these MEC neurons received inputs that originate from neurons in either structure. MEC neurons actually reacted with responses to both $\mathrm{PrS}$ and $\mathrm{PaS}$ stimulation, respectively, demonstrating convergence of $\mathrm{PrS}$ and $\mathrm{PaS}$ inputs on principal neurons of all MEC layers.

We thus conclude that the response properties of the individual principal neurons as recorded with electrical stimulation predominantly reflect monosynaptic inputs that originate in $\operatorname{PrS}$ and $\mathrm{PaS}$, and that individual neurons in all layers receive convergent inputs from both sources.

\section{Discussion}

Initial descriptions of the projections from PrS and PaS to MEC focused on their striking laminar terminal distribution with $\operatorname{PrS}$ projecting to LI and LIII, and PaS projecting to LII, assuming that this indicated target specificity (Köhler, 1984; Caballero-Bleda and Witter, 1994). Only more recently it was recognized that both inputs may not only target neurons in LII and LIII (Tolner et al., 2007) but that LV neurons are also among the potential postsynaptic targets for PrS axons in MEC (Wouterlood et al., 2004). Since recent in vivo data revealed that principal neurons in all
MEC layers show directional modulation (Sargolini et al., 2006; Boccara et al., 2010) we engaged in a systematic study of the interactions of inputs from $\mathrm{PrS}$ and $\mathrm{PaS}$ with individual neurons in all layers of MEC. We used a newly developed combined anatomical and electrophysiological in vitro approach that allowed the selection of optimal slices in which the relevant connectivity was maintained. Anterograde labeling of the relevant projections allowed the angle and dorsoventral levels of slices to be optimized, to assure that connectivity between MEC and layers II/III of PrS and PaS was maintained within the slice. VSD imaging provided for an efficient assessment of the patterns of projections from $\mathrm{PrS}$ and $\mathrm{PaS}$ with the MEC network (polysynaptic or monosynaptic), in terms of overall efficacy and laminar profiles. However, this technique is not sensitive enough to examine the connections at a single-neuron level and to unequivocally decide whether responses resulted from monosynaptic inputs. Therefore, the inputs of PrS and $\mathrm{PaS}$ were also analyzed using singleneuron recordings in MEC, while stimulating PrS or PaS extracellularly. Extracellular stimulation may produce false positive results due to volume conduction and orthodromic or antidromic stimulation of passing fibers. Glutamate uncaging was used to control for these possible confounds. By retrograde labeling of neurons, we were able to record from identified hippocampal projection neurons in the same experiments. Our first conclusion is that principal neurons in all four main MEC cell layers receive monosynaptic inputs from $\mathrm{PrS}$ and $\mathrm{PaS}$. In addition, principal neurons in all layers receive convergent inputs from both sources (Fig. 7).

LII and LIII principal neurons receive PrS and PaS inputs onto local dendrites (Caballero-Bleda and Witter, 1994) likely leading to integration of directional information as reflected by their in vivo firing patterns (Hafting et al., 2005; Sargolini et al., 2006; Solstad et al., 2008). Among the targeted cells are hippocampal projection neurons, implying that directional information from $\mathrm{PrS}$ and $\mathrm{PaS}$ can influence all subregions of the hippocampal formation (Witter, 2011).

Principal pyramidal neurons in MEC LV receive convergent inputs from both PrS (Wouterlood et al., 2004) and PaS on their apical dendrites (Fig. 7). Similar to what has been proposed for LV pyramidal neurons in the neocortex, the apical tuft may signal temporal coincidence between inputs from PrS and PaS (Mehta, 2004). In this way, LV pyramidals may integrate $\mathrm{PrS}$ and $\mathrm{PaS}$ inputs with those terminating on their basal dendrites that represent hippocampal and retrosplenial information (Kloosterman et al., 2004; Jones and Witter, 2007; Spruston, 2008; Larkum et al., 2009).

The finding that LVI principal neurons receive inputs from $\mathrm{PrS}$ and $\mathrm{PaS}$ is unexpected since most of them do not have an apical dendrite reaching superficial layers (Canto and Witter, 2012). They may, however, be innervated by axons from PrS and PaS that travel through LVI on their way to either the angular 
bundle or to their entorhinal terminal positions (Honda and Ishizuka, 2004; our unpublished observations). The role of $\operatorname{PrS}$ and $\mathrm{PaS}$ inputs targeting LVI neurons is not clear. The fact that directionally modulated cells are present in this layer (Sargolini et al., 2006) strengthens the here proposed relationship between directional properties of MEC principal neurons and inputs from PrS and $\mathrm{PaS}$.

This common input to neurons in all layers thus constitutes the architecture that may underlie observed directional signals in neurons in all layers of MEC. We further suggest that this common input contributes to the frequent consistency of grid cell orientation in simultaneously recorded grid cells across layers of MEC (Sargolini et al., 2006), although local interlayer connectivity (Witter, 2011) will potentially be relevant as well.

To our knowledge, this is the first study indicating that principal neurons in all layers of a multilayered cortex may all receive a common set of cortical inputs. This appears in contrast to the organization reported, for example, in the retrosplenial cortex, where apical dendrites of deeper principal neurons receive inputs onto their apical tufts that differ from inputs targeting dendrites of LII neurons (Wyss et al., 1990; Ichinohe and Rockland, 2002).

The study also shows that principal neurons in different layers integrate incoming information in a frequency-dependent manner and that the integration properties are layer specific with LII principal neurons being particularly different. In response to single stimuli the decay time and thereby the half-width of the eEPSP of LII principal neurons is significantly different from all other layers. LII neurons further have a frequency-dependent hyperpolarizing "rebound" event following the decay. LII neurons will thus inactivate faster after elimination of the input signal compared with neurons in all other MEC layers and summation of synaptic inputs is less likely to occur. This is also reflected in the particular response of LII principal neurons to repetitive PrS and $\mathrm{PaS}$ stimulation compared with other layers. LII stellate cells show a tendency to depress their responses when stimulated at frequencies between 10 and $40 \mathrm{~Hz}$ and only at $100 \mathrm{~Hz}$ stimulation they facilitate from the first to the last eEPSP. Both short-term depression and frequency-dependent plasticity allow LII principal neurons to react to subtle changes in the firing frequencies of $\mathrm{PrS}$ and PaS afferents and to integrate these inputs when the beginning of the two stimuli are closely matched in time (Abbott et al., 1997; Rothman et al., 2009). In contrast, postsynaptic responses of LIII principal neurons facilitate in response to frequencies $>10 \mathrm{~Hz}$ and principal neurons in LV and LVI have a tendency to facilitate at all frequencies tested, indicating that independent of the frequency of the input, arriving synaptic events will be easily summated over time (Jones and Woodhall, 2005).

The differences in integrative properties between neurons in LII and in the remainder of the layers, likely reflect layer differences in biophysical properties of principal neurons (Canto and Witter, 2012). These may include voltage-sensitive potassium channels (Kv1) and a nonselective cation channel (Ih) (Dickson et al., 2000; Monaghan et al., 2001), which are either lacking in the other layers or not activated by $\mathrm{PrS}$ and $\mathrm{PaS}$ stimulation (Shah et al., 2004).

We occasionally recorded from interneurons in layers II and III and observed that these received monosynaptic inputs from PrS or PaS. Although a systematic study of these interactions awaits further study, we suggest that laminar differences in local inhibitory networks (Wouterlood, 2002; Klausberger, 2009) contribute to layer-specific responses of principal cells as well. Indeed, marked differences in the efficacy of inhibitory networks have been reported in that the LII network is governed by strong inhibition, which is less obvious in deeper layers III and V (Dhillon and Jones, 2000; Couey, 2012). Feedforward and feedback inhibition from interneurons can also underline the observed difference in decay time and plasticity of LII principal neurons compared with other layers. The striking layer-specific response properties of principal neurons in MEC upon stimulation of PrS and $\mathrm{PaS}$, differentiating in particular LII from the other layers, correlate with in vivo findings that LII harbors almost exclusively grid cells with a very low percentage of head direction cells, whereas LIII-LVI contain mixed populations of spatially modulated neurons (Sargolini et al., 2006; Boccara et al., 2010).

\section{References}

Abbott LF, Varela JA, Sen K, Nelson SB (1997) Synaptic depression and cortical gain control. Science 275:220-224. Medline

Beed P, Bendels MH, Wiegand HF, Leibold C, Johenning FW, Schmitz D (2010) Analysis of excitatory microcircuitry in the medial entorhinal cortex reveals cell-type-specific differences. Neuron 68:1059-1066. CrossRef Medline

Bendels MH, Beed P, Leibold C, Schmitz D, Johenning FW (2008) A novel control software that improves the experimental workflow of scanning photostimulation experiments. J Neurosci Methods 175:44-57. CrossRef Medline

Bendels MH, Beed P, Schmitz D, Johenning FW, Leibold C (2010) Detection of input sites in scanning photostimulation data based on spatial correlations. J Neurosci Methods 192:286-295. CrossRef Medline

Boccara CN, Sargolini F, Thoresen VH, Solstad T, Witter MP, Moser EI, Moser MB (2010) Grid cells in pre- and parasubiculum. Nat Neurosci 13:987-994. CrossRef Medline

Bonnevie T, Fyhn M, Hafting T, Derdikman D, Moser EI, Moser M-B (2011) Spatial correlation structure of grid cells after hippocampal inactivation. Soc. Neurosci Abstr 37:726.14.

Brandon MP, Bogaard AR, Libby CP, Connerney MA, Gupta K, Hasselmo ME (2011) Reduction of theta rhythm dissociates grid cell spatial periodicity from directional tuning. Science 332:595-599. CrossRef Medline

Burgess N, O'Keefe J (2011) Models of place and grid cell firing and theta rhythmicity. Curr Opin Neurobiol 21:734-744. CrossRef Medline

Burgess N, Barry C, O'Keefe J (2007) An oscillatory interference model of grid cell firing. Hippocampus 17:801-812. CrossRef Medline

Caballero-Bleda M, Witter MP (1993) Regional and laminar organization of projections from the presubiculum and parasubiculum to the entorhinal cortex: an anterograde tracing study in the rat. J Comp Neurol 328: 115-129. CrossRef Medline

Caballero-Bleda M, Witter MP (1994) Projections from the presubiculum and the parasubiculum to morphologically characterized entorhinalhippocampal projection neurons in the rat. Exp Brain Res 101:93-108. Medline

Canto CB, Witter MP (2012) Cellular properties of principal neurons in the rat entorhinal cortex. II. The medial entorhinal cortex. Hippocampus 22:1277-1299. CrossRef Medline

Canto CB, Wouterlood FG, Witter MP (2008) What does the anatomical organization of the entorhinal cortex tell us? Neural Plast 2008:381243. Medline

Couey JJ (2012) Medial entorhinal cortex layer II stellate cells are embedded within a recurrent inhibitory network. Soc Neurosci Abstr 38:702.706.

Dhillon A, Jones RS (2000) Laminar differences in recurrent excitatory transmission in the rat entorhinal cortex in vitro. Neuroscience 99:413422. CrossRef Medline

Dickson CT, Magistretti J, Shalinsky MH, Fransén E, Hasselmo ME, Alonso A (2000) Properties and role of $\mathrm{I}(\mathrm{h})$ in the pacing of subthreshold oscillations in entorhinal cortex layer II neurons. J Neurophysiol 83:2562-2579. Medline

Fuhs MC, Touretzky DS (2006) A spin glass model of path integration in rat medial entorhinal cortex. J Neurosci 26:4266-4276. CrossRef Medline

Garden DL, Dodson PD, O'Donnell C, White MD, Nolan MF (2008) Tuning of synaptic integration in the medial entorhinal cortex to the organization of grid cell firing fields. Neuron 60:875-889. CrossRef Medline

González-Burgos G, Barrionuevo G, Lewis DA (2000) Horizontal synaptic connections in monkey prefrontal cortex: an in vitro electrophysiological study. Cereb Cortex 10:82-92. CrossRef Medline 
Grinvald A, Frostig RD, Lieke E, Hildesheim R (1988) Optical imaging of neuronal activity. Physiol Rev 68:1285-1366. Medline

Hafting T, Fyhn M, Molden S, Moser MB, Moser EI (2005) Microstructure of a spatial map in the entorhinal cortex. Nature 436:801-806. CrossRef Medline

Honda Y, Ishizuka N (2004) Organization of connectivity of the rat presubiculum: I. Efferent projections to the medial entorhinal cortex. J Comp Neurol 473:463-484. CrossRef Medline

Ichinohe N, Rockland KS (2002) Parvalbumin positive dendrites co-localize with apical dendritic bundles in rat retrosplenial cortex. Neuroreport 13:757-761. CrossRef Medline

Iijima T, Witter MP, Ichikawa M, Tominaga T, Kajiwara R, Matsumoto G (1996) Entorhinal-hippocampal interactions revealed by real-time imaging. Science 272:1176-1179. CrossRef Medline

Jones BF, Witter MP (2007) Cingulate cortex projections to the parahippocampal region and hippocampal formation in the rat. Hippocampus 17:957-976. CrossRef Medline

Jones RS, Woodhall GL (2005) Background synaptic activity in rat entorhinal cortical neurones: differential control of transmitter release by presynaptic receptors. J Physiol 562:107-120. Medline

Kerr KM, Agster KL, Furtak SC, Burwell RD (2007) Functional neuroanatomy of the parahippocampal region: the lateral and medial entorhinal areas. Hippocampus 17:697-708. CrossRef Medline

Klausberger T (2009) GABAergic interneurons targeting dendrites of pyramidal cells in the CA1 area of the hippocampus. Eur J Neurosci 30:947957. CrossRef Medline

Kloosterman F, van Haeften T, Lopes da Silva FH (2004) Two reentrant pathways in the hippocampal-entorhinal system. Hippocampus 14: 1026-1039. CrossRef Medline

Koenig J, Linder AN, Leutgeb JK, Leutgeb S (2011) The spatial periodicity of grid cells is not sustained during reduced theta oscillations. Science 332: 592-595. CrossRef Medline

Koganezawa N, Taguchi A, Tominaga T, Ohara S, Tsutsui K, Witter MP, Iijima T (2008) Significance of the deep layers of entorhinal cortex for transfer of both perirhinal and amygdala inputs to the hippocampus. Neurosci Res 61:172-181. CrossRef Medline

Köhler C (1984) Morphological details of the projection from the presubiculum to the entorhinal area as shown with the novel PHA-L immunohistochemical tracing method in the rat. Neurosci Lett 45:285-290. CrossRef Medline

Köhler C (1985) Intrinsic projections of the retrohippocampal region in the rat brain. I. The subicular complex. J Comp Neurol 236:504-522. CrossRef Medline

Köhler C (1986) Intrinsic connections of the retrohippocampal region in the rat brain. II. The medial entorhinal area. J Comp Neurol 246:149-169. CrossRef Medline

Kononenko NL, Pflüger HJ (2007) Dendritic projections of different types of octopaminergic unpaired median neurons in the locust metathoracic ganglion. Cell Tissue Res 330:179-195. CrossRef Medline

Larkum ME, Nevian T, Sandler M, Polsky A, Schiller J (2009) Synaptic integration in tuft dendrites of layer 5 pyramidal neurons: a new unifying principle. Science 325:756-760. CrossRef Medline

McNaughton BL, Battaglia FP, Jensen O, Moser EI, Moser MB (2006) Path integration and the neural basis of the 'cognitive map'. Nat Rev Neurosci 7:663-678. CrossRef Medline

Mehta MR (2004) Cooperative LTP can map memory sequences on dendritic branches. Trends Neurosci 27:69-72. CrossRef Medline
Monaghan MM, Trimmer JS, Rhodes KJ (2001) Experimental localization of Kvl family voltage-gated $\mathrm{K}+$ channel alpha and beta subunits in rat hippocampal formation. J Neurosci 21:5973-5983. Medline

Rothman JS, Cathala L, Steuber V, Silver RA (2009) Synaptic depression enables neuronal gain control. Nature 457:1015-1018. CrossRef Medline

Sargolini F, Fyhn M, Hafting T, McNaughton BL, Witter MP, Moser MB, Moser EI (2006) Conjunctive representation of position, direction, and velocity in entorhinal cortex. Science 312:758-762. CrossRef Medline

Shah MM, Anderson AE, Leung V, Lin X, Johnston D (2004) Seizureinduced plasticity of h channels in entorhinal cortical layer III pyramidal neurons. Neuron 44:495-508. CrossRef Medline

Sherwood NM, Timiras PS (1970) Atlas of the developing rat brain. Berkeley, CA: University of California.

Shibata H (1993) Direct projections from the anterior thalamic nuclei to the retrohippocampal region in the rat. J Comp Neurol 337:431-445. CrossRef Medline

Solstad T, Boccara CN, Kropff E, Moser MB, Moser EI (2008) Representation of geometric borders in the entorhinal cortex. Science 322:18651868. CrossRef Medline

Spruston N (2008) Pyramidal neurons: dendritic structure and synaptic integration. Nat Rev Neurosci 9:206-221. CrossRef Medline

Stackman RW, Taube JS (1998) Firing properties of rat lateral mammillary single units: head direction, head pitch, and angular head velocity. J Neurosci 18:9020-9037. Medline

Taube JS (1995) Head direction cells recorded in the anterior thalamic nuclei of freely moving rats. J Neurosci 15:70-86. Medline

Taube JS (2007) The head direction signal: origins and sensory-motor integration. Annu Rev Neurosci 30:181-207. CrossRef Medline

Tolner EA, Frahm C, Metzger R, Gorter JA, Witte OW, Lopes da Silva FH, Heinemann U (2007) Synaptic responses in superficial layers of medial entorhinal cortex from rats with kainate-induced epilepsy. Neurobiol Dis 26:419-438. CrossRef Medline

Van Groen T, Wyss JM (1995) Projections from the anterodorsal and anteroventral nucleus of the thalamus to the limbic cortex in the rat. J Comp Neurol 358:584-604. CrossRef Medline

van Haeften T, Wouterlood FG, Jorritsma-Byham B, Witter MP (1997) GABAergic presubicular projections to the medial entorhinal cortex of the rat. J Neurosci 17:862-874. Medline

Vann SD (2010) Re-evaluating the role of the mammillary bodies in memory. Neuropsychologia 48:2316-2327. CrossRef Medline

Witter MP (2011) Connectivity of the hippocampus. In: Hippocampal microcircuits: a computational modeler's resource book (Cutsuridis V, Graham B, Cobb S, Vida I, eds), pp 5-26. New York: Springer.

Witter MP, Amaral DG (2004) Hippocampal formation. In: The rat nervous system, Ed 3 (Paxinos G, ed), pp 635-704. San Diego: Academic.

Wouterlood FG (2002) Spotlight on the neurons (I): cell types, local connectivity, microcircuits, and distribution of markers. In: The parahippocampal region: organization and role in cognitive function (Witter MP, Wouterlood FG, eds), pp 61-88. Oxford: Oxford UP.

Wouterlood FG, van Haeften, Eijkhoudt M, Baks-Te-Bulte L, Goede PH, Witter MP (2004) Input from the presubiculum to dendrites of layer-V neurons of the medial entorhinal cortex of the rat. Brain Res 1013:1-12. CrossRef Medline

Wyss JM, Van Groen T, Sripanidkulchai K (1990) Dendritic bundling in layer I of granular retrosplenial cortex: intracellular labeling and selectivity of innervation. J Comp Neurol 295:33-42. CrossRef Medline 